\title{
Effect of Discrete Ribs on Heat Transfer and Friction Inside Narrow Rectangular Cross Section Cooling Passage (AR=1:5) of Gas Turbine Blade
}

\author{
Karthik Krishnaswamy, Srikanth Salyan
}

\begin{abstract}
The performance of a gas turbine during the service life can be enhanced by cooling the turbine blades efficiently. The objective of this study is to achieve high thermohydraulic performance (THP) inside a cooling passage of a turbine blade having aspect ratio (AR) 1:5 by using discrete $W$ and $V$-shaped ribs. Hydraulic diameter $\left(D_{h}\right)$ of the cooling passage is $50 \mathrm{~mm}$. Ribs are positioned facing downstream with angle-of-attack $(\alpha)$ of $30^{\circ}$ and $45^{\circ}$ for discrete $W$-ribs and discerte $V$-ribs respectively. The rib profiles with rib height to hydraulic diameter ratio $\left(e / D_{h}\right)$ or blockage ratio 0.06 and pitch $(P) 36 \mathrm{~mm}$ are tested for Reynolds number (Re) range 30000-75000. Analysis reveals that, area averaged Nusselt numbers of the rib profiles are comparable, with maximum difference of $6 \%$ at $\operatorname{Re} 30000$, which is within the limits of uncertainty. Variation of local heat transfer coefficients along the stream exhibited a saw tooth profile, with discrete W-ribs exhibiting higher variations. Along spanwise direction, discrete $V$-ribs showed larger variations. Maximum variation in local heat transfer coefficients is estimated to be 25\%. For experimented Re range, friction loss for discrete $W$-ribs is higher than discrete-V ribs. Rib profiles exhibited superior heat transfer capabilities. The best $\mathrm{Nu} / \mathrm{Nu}$ o achieved for discrete $\mathrm{V}$ ribs is 3.4 and discrete $W$-ribs is 3.6. In view of superior heat transfer capabilities, ribs can be deployed in cooling passages near the leading edge, where the temperatures are very high. The best THP achieved is 3.2 for discrete $V$-ribs and 3 for discrete $W$-ribs at $\operatorname{Re} 30000$. The ribs can also enhance the power-toweight ratio as they can produce high thermohydraulic performances for low blockage ratios.
\end{abstract}

Keywords: Reynolds number, Discrete $W$ and V-ribs, Nusselt number ratio, Heat transfer coefficient, Friction factor ratio, Thermohydraulic Performance

\section{I.INTRODUCTION}

Gas turbine engine performance improves with turbine inlet temperatures (TIT). In general, the operating temperatures of current generation gas turbines are very high. In many cases, temperatures are close to melting point, and therefore increase in TIT is possible only by cooling the turbine blades efficiently. Turbine blade surfaces are cooled internally and externally by extracting air from the compressor.

Manuscript received on August 17, 2021.

Revised Manuscript received on August 28, 2021.

Manuscript published on August 30, 2021.

* Correspondence Author

Karthik Krishnaswamy*, Research Scholar, Department of Mechanical Engineering, National Institute of Technology, Tiruchirappalli, India. Email: karthikkrishnaswamy79@gmail.com

Srikanth Salyan, Assistant Professor, Department of Aeronautical Engineering, Dayananda Sagar College of Engineering, Bangalore, India. E-mail: srikanthsalyan@gmail.com

(C) The Authors. Published by Blue Eyes Intelligence Engineering and Sciences Publication (BEIESP). This is an open access article under the CC BY-NC-ND license (http://creativecommons.org/licenses/by-nc-nd/4.0/)
Drawing out excess air from the compressor for cooling will reduce the power output and hence the cooling process is required to be optimized to achieve maximum heat transfer. Inside a cooling passage, ribs or so called turbulators are positioned on the inner wall surfaces to improve the heat transfer. As the coolant flows over the ribs, turbulence is generated which improves the heat transfer. The magnitude of turbulence is dependent on the physical parameters of the rib such as shape, height, length, orientation, pitch, and number of walls fixed with ribs. The research output obtained by various researchers are discussed in detail further. Han et al. [1] performed experimental studies with nine rib profiles and established that, friction was highest for inverted V-ribs and heat transfer augmentation was highest for in-line V-ribs. Lau et al. [2] assessed the rib performances in a channel of aspect ratio 1:1 and concluded that, heat transfer enhancement was greatest for V-ribs and friction was greatest for inverted Vribs. It was also concluded that, increase in pitch reduced the heat transfer improvement and friction loss. Han and Zhang [3] studied the performance of different rib profiles and presented that, for $R e$ range 15000-90000 in a cooling channel having aspect ratio 1:1, broken ribs exhibited best performance and ribs oriented at $60^{\circ}$ showed better heat transfer capabilities. Ekkad and Han [4] performed experiments with different ribs in square cross section channel having two passes. The authors presented that, for Re range 6000-60000, V-broken ribs produced better enhancements in first pass and the second pass enhancements were $200-300 \%$ greater than first pass view intensification of secondary flows by $180^{\circ}$ turn. Tzeng and Mao [5] performed experimental studies to comprehend flow and thermal parameters for staggered half V-ribs in four pass serpentine channel for Re 20000 and 40000 . They indicated that, effects of ribs on heat extraction were present in all passes. Besides, they also reported that, coolant when pressurized performed better. Al-Hadhrami et al. [6] using a channel of aspect ratio 2:1 tested different V-shaped ribs $(P / e=10)$ and concluded that, augmentation was highest for downstream facing parallel V-shaped ribs oriented at $45^{\circ}$ to coolant flow. Wright et al. [7] experimented different ribs $(P / e=10)$ in a cooling channel $(A R=4)$. They reported that, for $R e$ up to 40000 , W-shaped ribs produced high enhancement and friction whereas discrete $\mathrm{V}$ and $\mathrm{W}$-ribs produced best thermal performance.

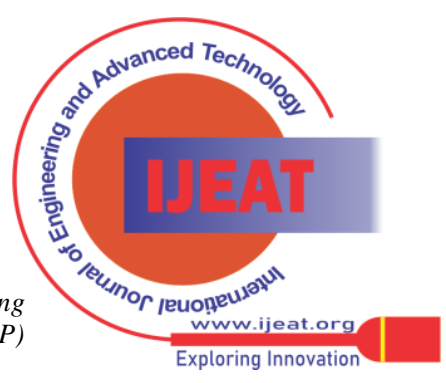




\section{Effect of Discrete Ribs on Heat Transfer and Friction Inside Narrow Rectangular Cross Section Cooling Passage (AR=1:5) of Gas Turbine Blade}

Gao and Sunden [8] assessed the flow patterns of six rib profiles, which included $\mathrm{V}$ and inverted $\mathrm{V}$-ribs in a 1:8 aspect ratio channel. Results for $R e$ range 1000-5800 revealed that, V-ribs facing upstream resulted in highest heat transfer augmentation. Fu et al. [9] assessed the capabilities of $45^{\circ}$ angled ribs in cooling passages having aspect ratios 1:4 and 1:2. The authors noticed that, Nusselt numbers of ribbed wall under stationary condition were 2.5-3 times greater than that predicted using Dittus-Boelter correlation for the Re ranging from 5000-40000. Akhanda M.A.R et al. [10] conducted experiments in a square duct for $R e$ ranging from 46000 to 52000 with square ribs and concluded that, heat transfer and pressure drop due to ribs were $15 \%$ and $6 \%$ greater than smooth wall duct. Maurer and Wolfersdorf [11] by utilizing thermochromic liquid crystal technique analyzed the performances of V-ribs in a channel $(A R=2: 1)$ and established that, for $R e$ between 95000-500000 and $P / e=10$, ribs with lesser height fixed on one wall delivered the highest performances. Gupta et al. [12] concluded that, amongst orthogonal, saw tooth and $60^{\circ} \mathrm{V}$-broken ribs, augmentation was highest for $\mathrm{V}$-broken ribs for $R e$ range 10000 to 30000 . Sriharsha et al. [13] tested orthogonal ribs and $60^{\circ}$ broken ribs for $R e$ up to 30000 by using a square cross section channel. Authors brought out that, broken Vribs with $P / e=10$ generated highest augmentation. Alkhamis et al. [14] evaluated angled and V-shaped ribs for their performances up to $R e 400000$ and confirmed that, $45^{\circ} \mathrm{V}$ shaped ribs produced highest performance. Baraskar et al. [15] examined the performance characteristics of $60^{\circ} \mathrm{V}$-ribs in aspect ratio 1:8 channel for $R e$ up to 14000 . The authors reported that, heat transfer and friction for $60^{\circ} \mathrm{V}$ - ribs were 2.57 and 2.85 times greater than smooth wall case at $R e$ 14000. Lamont and Kaminski [16] with the help of transient liquid crystal technique compared three rib profiles in a diverging channel and confirmed that, V-ribs at $45^{\circ}$ to coolant flow provided uniform and higher levels of heat transfer than orthogonal and $60^{\circ}$ ribs at $R e$ 28000. Kumar and Amano [17] studied the effects of V-ribs in a channel $(A R=1: 1)$ and concluded that, broken ribs augmented heat transfer better than continuous ribs and performances of ribs pointing upstream was best. Xie et al. [18] investigated $45^{\circ}$ mid truncated and $\mathrm{V}$-shaped ribs inside aspect ratio 1:1 channel for $R e$ up to 50000. Their investigation revealed that, mid-truncated angled ribs exhibited best performance and mid-truncated V-ribs facing downstream provided best augmentation. Smith et al. [19] assessed the flow patterns for $45^{\circ}$ angled ribs $(P / e=10)$ in cooling channels with different cross section. For the experimented Re range 4000130000, they noticed that, secondary flows were well developed in the channel with 1:6 aspect ratio. Ghodake et al. [20] examined the augmentation capabilities of different rib profiles in a rectangular duct. The authors concluded that, rectangular tape ribs and $45^{\circ}$ broken V-ribs $(P / e=8.3)$ delivered the best heat transfer enhancement. Abraham and Vedula [21] used a converging channel to establish the friction loss and heat transfer for $45^{\circ}$ continuous $\mathrm{W}$ and $\mathrm{V}$ shaped rib turbulators. The authors reported large differences in heat transfer along the span for V-ribs and also concluded that, performances of the rib profiles were within the range of uncertainty for optimum pitch to height ratio 10. Prashant et al. [22] studied the performances of four dissimilar profiled ribs and confirmed that, for $R e$ range 19500-69000, performances exhibited by $45^{\circ} \mathrm{V}$-ribs and angled ribs were best when compared to other ribs. Ravi et al. [23] evaluated four distinct rib profiles that were inserted at 45 degrees to the flow direction inside a square cross section channel. According to the authors, $45^{\circ} \mathrm{V}$-shaped and angled ribs performed best in the Re range of 20000 to 70000. By using $90^{\circ}$ ribs, Honghu et al. [24] investigated the effect of three different e/Dh ratios on thermohydraulic performance inside a rotating square channel. For Re up to 40000 , the authors found that an e/Dh ratio of 0.1 yielded the best results. $\mathrm{V}$ and $\mathrm{W}$-ribs were tested in a channel $(\mathrm{AR}=1: 4)$ by Krishnaswamy and Sivan [25], and found that $45^{\circ} \mathrm{V}$ and $\mathrm{W}$-ribs with e/Dh values of 0.0729 and 0.0833 produced high thermal performances. Furthermore, the authors stated that W-ribs had the most non-uniformity in heat transport.

Novelty. The difference in height between the trailing and leading walls of a turbine blade increases towards the leading edge and decreases towards the trailing edge from the mid-chord due to the airfoil contour of the turbine blade. As the height difference grows, very tiny ribbed cooling passageways adjacent to the leading edge appear, with aspect ratios as high as 1:6 [19]. Following a thorough review of the literature, it was discovered that the vast majority of cooling studies conducted to date have been limited to square and narrow ribbed cooling passages with aspect ratios up to $1: 2$, indicating that there is a need to assess friction and heat transfer in narrow cooling passages adjacent to the leading edge with aspect ratios less than 1:2. Another essential consideration is the efficient management of heat load in the leading edge of an airfoil. Thermal stresses in the regions adjacent to the leading edge are quite high due to high operating temperatures, therefore maximising heat transfer while minimising friction losses and coolant consumption is critical. Because the coolant is used for impingement and film cooling after leaving the ribbed channels, attempting to boost heat transfer by raising the rib height or lowering the rib pitch will simply increase friction, lowering thermohydraulic performance. Furthermore, the efficacy of impingement cooling and film cooling will deteriorate, reducing the turbine blade's effective service life. Considering the above factors, this work has been performed with an aim to achieve high thermohydraulic performance inside a ribbed passage $(A R=1: 5)$, which is geometrically similar to an actual cooling passage located closer to the turbine blade leading edge. To accomplish this, discrete upstream pointing $\mathrm{W}$ and V-ribs were chosen, and essential geometric factors such as pitch, height, and angle-of-attack were tuned to get the optimal outcomes. To the best of our knowledge, ribs with the geometry noted in table 1 have been evaluated for the first time in a ribbed cooling passage with an aspect ratio of $1: 5$, and the results for the $\mathrm{Re}$ range 30000-75000 are promising. 3.2 and 1.7 are the highest and lowest thermohydraulic performances, respectively.

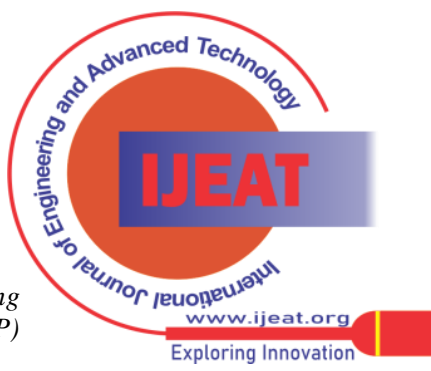


Table.1 Details of rib geometry

\begin{tabular}{|c|c|c|c|c|c|c|c|}
\hline \multirow{2}{*}{ Type of ribs } & \multirow{2}{*}{$\begin{array}{c}\text { Rib } \\
\text { Height } \\
\text { (e) }\end{array}$} & \multirow{2}{*}{$\begin{array}{c}\text { Pitch - } \\
\text { to- } \\
\text { height } \\
\text { ratio } \\
\text { (P/e) }\end{array}$} & \multirow{2}{*}{$\begin{array}{c}\text { Height } \\
\text {-to- hydraulic } \\
\text { diameter ratio } \\
\left(\mathrm{e} / \mathrm{D}_{\mathrm{h}}\right) \\
\end{array}$} & \multirow{2}{*}{$\begin{array}{c}\text { Angle } \\
\text { of attack } \\
(\alpha)\end{array}$} & \multicolumn{3}{|c|}{ Recommended range in literature } \\
\hline & & & & & $\mathbf{P} / \mathbf{e}$ & $\mathbf{e} / \mathbf{D}_{\mathbf{h}}$ & $\alpha$ \\
\hline Discrete 'V' & 3 & 12 & 0.06 & $45^{\circ}$ & \multirow{2}{*}{$5-15$} & \multirow{2}{*}{$0.05-0.1$} & \multirow{2}{*}{$30^{\circ}-60^{\circ}$} \\
\hline Discrete 'W' & 3 & 12 & 0.06 & $30^{\circ}$ & & & \\
\hline
\end{tabular}

\section{II.EXPERIMENTAL FACILITY}

The system designed for carrying out experiments is illustrated in figure 1. Centrifugal type blower is used to feed air to the system. A bleed valve and control valve are provided to control air flow. A calibrated venturimeter with U-tube water manometer is fitted in the mainline to determine the rate of flow. Downstream of venturimeter is connected to test section. Calibrated thermocouples are mounted at the inlet and outlet ends of test section to record coolant air temperature. Test section is divided into three sections namely developing, ribbed, and exit sections.

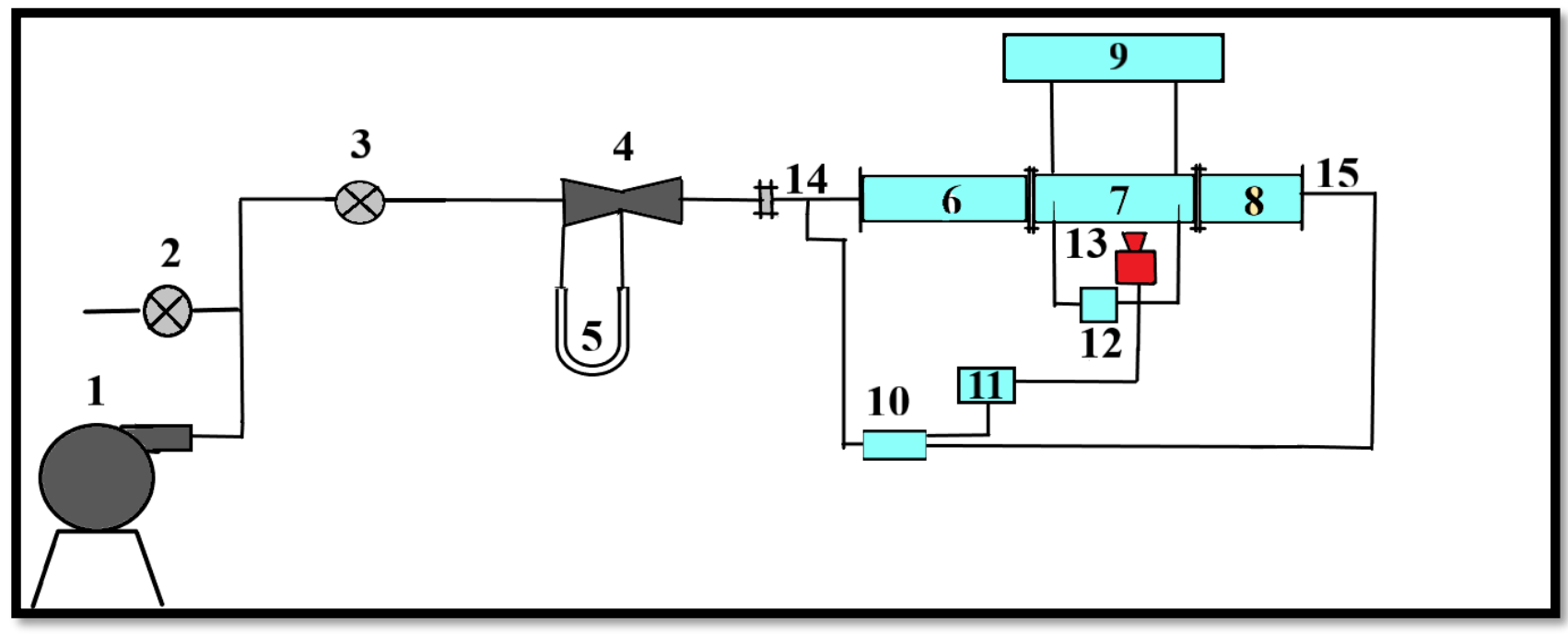
1. Blower
6. Developing section
2. Bypass Ball valve7. Ribbed section
3. Inlet ball valve
8. Exit section
9. DC Source
4. Venturimeter
10. Data logger
5. Manometer

11. Laptop

12. Differential Pressure Transmitter

13. Thermal Infrared camera

14. Inlet Thermocouples (K-Type)

15. Exit Thermocouples (K-Type)

\section{Fig.1 Schematic of experimental test facility}

Test facility is fabricated using $12 \mathrm{~mm}$ Perspex sheet, which possesses good strength, low thermal conductivity and ability to withstand temperatures up to $120^{\circ} \mathrm{C}$. Cross section ( $\mathrm{W} \mathrm{x} \mathrm{H}$ ) of test section is $30 \mathrm{~mm} \times 150 \mathrm{~mm}$ and the length is $1500 \mathrm{~mm}$. For development of flow, $600 \mathrm{~mm}$ long developing section is provided. Ribbed section comprising of two smooth and two ribbed walls is placed at the downstream end of developing section, which is $600 \mathrm{~mm}$ long. This section is provided with taps to facilitate pressure drop measurements with the help of pressure transmitter. Thereafter, $300 \mathrm{~mm}$ long exit section is provided to ensure that the coolant flow parameters remain unaffected view abrupt expansion of coolant air to atmosphere. The ribbed wall is prepared by using very low thickness stainless steel sheet $(0.2 \mathrm{~mm}$, Grade 304). Copper block $(25 \mathrm{~mm} \times 28 \mathrm{~mm}$ $\times 3 \mathrm{~mm}$ ) with brass stud is fixed to the opposite ends of ribbed wall. Ribbed walls are then connected to $1200 \mathrm{~W}$ (150 A, 8 V) Direct Current rectifier, which is used as the source of power. Due to very low thickness of ribbed wall $(0.2 \mathrm{~mm})$, negligible temperature difference was observed between inner and outer surfaces, therefore lateral heat conduction between the surfaces is not considered in this work. The effective area of ribbed wall is $400 \mathrm{~mm}$ x $30 \mathrm{~mm}$. Electrical resistance of each wall is less than $0.05 \Omega$. Figure 2 depicts the 3D model of the test section and ribs. Ribs are made from $3 \mathrm{~mm}$ balsa wood. Balsa wood is light, possesses high strength and used extensively in aero modeling and rib cooling studies [21]. Discrete V- ribs have two rib arms and discrete W-ribs have four rib arms made into two V-shapes. Arms of both ribs are square in cross section ( $3 \mathrm{~mm} \times 3$ $\mathrm{mm}$ ). Two arms of discrete V-ribs are positioned with a gap of $3 \mathrm{~mm}$ along centerline. Similarly, the two V-shapes of the discrete $\mathrm{W}$-ribs are positioned with a gap of $3 \mathrm{~mm}$ along the centerline. Silicone sealant has been utilized to fix the ribs to the wall surface.

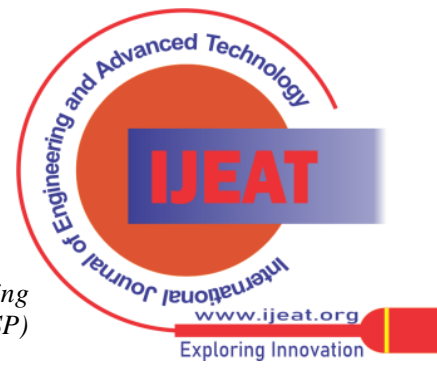




\section{Effect of Discrete Ribs on Heat Transfer and Friction Inside Narrow Rectangular Cross Section Cooling Passage (AR=1:5) of Gas Turbine Blade}

The two ribbed walls are then placed over the perspex sheet and held in position by fasteners. Additionally, heat resistant silicone tapes are also used to prevent air leaks. Exposed surfaces are coated with matt finish black paint to obtain

high emissivity. A thermal imaging camera has been used in the present work to measure the surface temperatures of the ribbed walls.

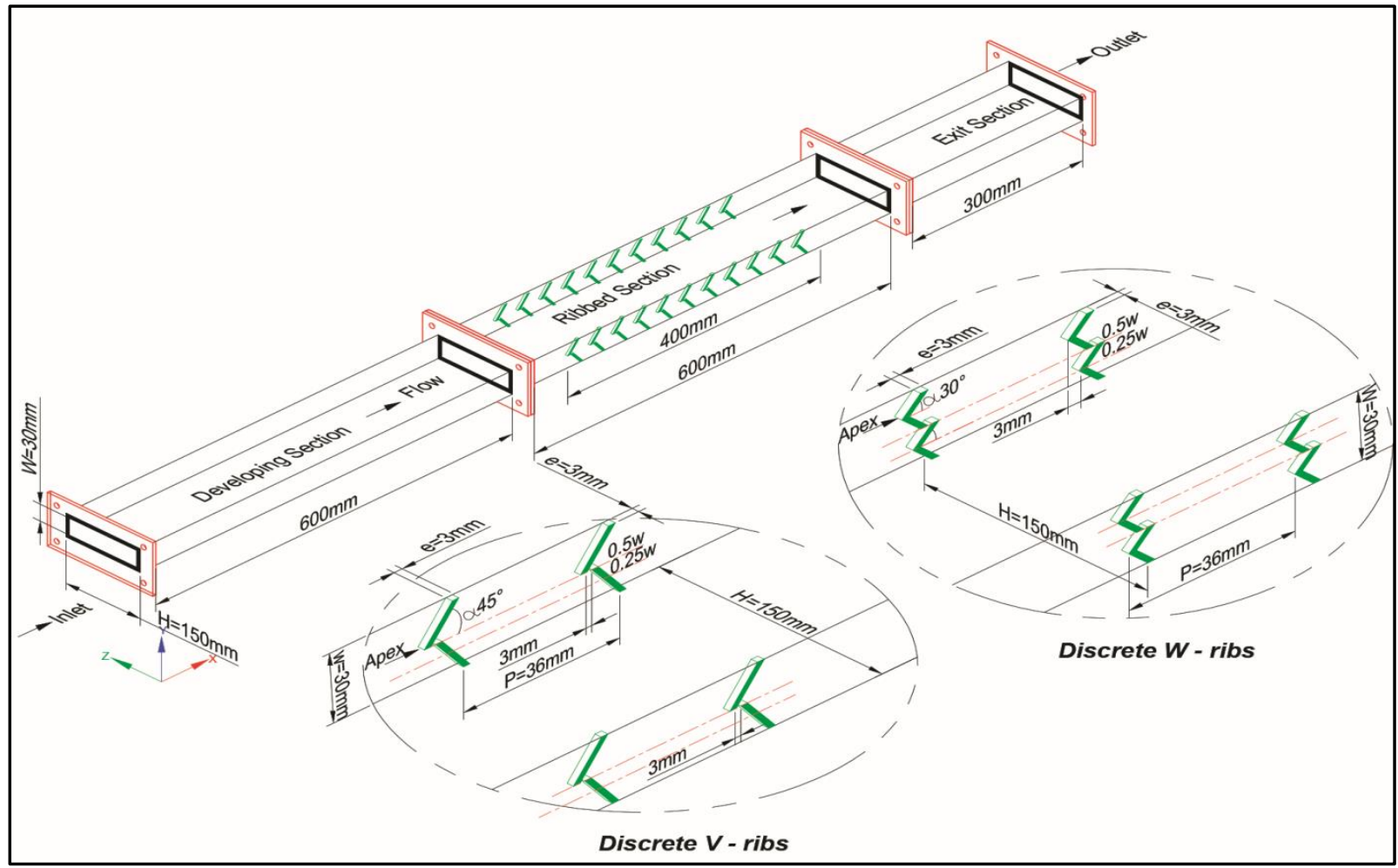

Fig.2 Test section model

\section{III.METHODOLOGY}

To produce the differential pressure head matching to Re under investigation, the coolant flow rate is changed. After the flow inside the test section has stabilised, the power source is turned on, and critical parameters such as ribbed wall temperatures, pressure drop across the ribbed section, inlet/exit bulk air temperatures, voltage drop across the copper blocks, and coolant velocity are recorded after 30 minutes. The infrared camera is then used to record ribbed wall images, which are then analysed to establish local wall temperatures. After determining wall temperatures, thermal hydraulic performances are estimated by using following equations

Reynolds number is given by Eq. (1)

$R e=\frac{\rho v D_{h}}{\mu}$

Convective and Radiation losses $\left(Q_{\text {loss }}\right)$ are deducted from the heat input $\left(Q_{\text {input }}=V I\right)$ for determining net heat input $\left(Q_{n e t}\right)$ to the ribbed walls. Maximum heat loss of $10 \%$ is observed at Reynolds number 30000.

Inlet/exit air temperatures measured by thermocouples are verified using energy balance Eq. (2)

$Q_{\text {net }}=\dot{m} c_{p}\left(T_{\text {bin }}-T_{\text {bout }}\right)$

Coolant air temperature at a particular location is obtained by interpolating the inlet and exit air temperatures. Air temperature at a particular cross section of the ribbed wall is assumed to be constant. After determining the local wall and coolant air temperatures, local heat transfer coefficients $(h)$ are obtained by using Eq. (3). Subsequently, area averaged Nusselt numbers $(\mathrm{Nu})$ for the smooth and ribbed walls are obtained by using Eq. (4) and Eq. (5) respectively.

$N u_{s}=\frac{\bar{h}_{s} D_{h}}{K}$

$N u=\frac{\bar{h} D_{h}}{K}$

Nusselt numbers calculated are then normalized with Dittus-

Boelter correlation represented by Eq. (6)

$N u_{o}=0.023 \operatorname{Re}^{0.8} \operatorname{Pr}^{0.4}$

Friction factor for the smooth and ribbed walls are determined from Eq. (7) and Eq. (8)

$f_{s}=\frac{\Delta P_{s} D_{h}}{2 \rho L v^{2}}$

$f=\frac{\Delta P D_{h}}{2 \rho L v^{2}}$

Friction factors are then normalized with Blasius equation represented by Eq. (9)

$f_{o}=0.079 R e^{-1 / 4}$

The Thermohydraulic performances at constant pumping power are then determined by using Eq. (10) and Eq. (11)

$\eta_{s}=\frac{\left(N u / N u_{s}\right)}{\left(f / f_{s}\right)^{1 / 3}}$

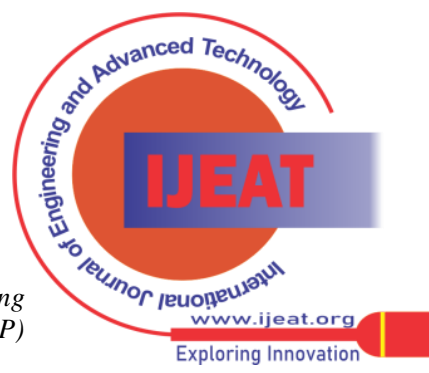




$$
\eta_{o}=\frac{\left(\mathrm{Nu} / \mathrm{Nu} u_{o}\right)}{\left(f / f_{o}\right)^{1 / 3}}
$$

Uncertainty Estimation. The uncertainty in the Nusselt number and friction factor recorded in this study is primarily due to measurement errors in coolant flow rate and ribbed wall temperatures. The percentage error in measuring coolant flow rate by venturimeter and wall temperatures by thermal camera was estimated using a hot wire anemometer and a calibrated thermocouple (K-type). The pressure difference across the manometer attached to the venturimeter determines the coolant flow rate. The velocity of coolant over the manometer that corresponds to a static differential head is compared to the velocity measured by the anemometer. The error observed ranged from $0.63 \mathrm{~m} / \mathrm{s}$ to $1.2 \mathrm{~m} / \mathrm{s}$ over the range of $\mathrm{Re}$ tested. A calibrated thermocouple is fixed to a stainless steel metal sheet $(0.2$ mm, Grade 304) covered with matt finish black paint used to paint the ribbed walls to estimate the error in wall temperature measurement. The stainless steel sheet is then gradually electrified in steps up to $100^{\circ} \mathrm{C}$ using the power source. The camera and thermocouple are used to measure steady state temperatures. At $100^{\circ} \mathrm{C}$, there is a maximum error of $3^{\circ} \mathrm{C}$ between camera and thermocouple data. A thermo water bath is used to calibrate the thermocouples used for measurement. The errors are found to be within $\pm 0.05^{\circ} \mathrm{C}$. Table 2 highlights the precision and variety of measuring tools used in this study. The highest uncertainty in estimating the Nusselt number is 9.5 percent and friction is $7 \%$ for Re 30000 using the methods described by Kline and McClintock [26].

Table.2 Details of Measuring Instruments

\begin{tabular}{|c|c|c|c|}
\hline Instruments & Type & Accuracy & Range \\
\hline Voltage Multimeter & M 3900, M/s Mastech & $\pm 0.5 \%$ & $200 \mathrm{mV}$ to $1000 \mathrm{~V}$ \\
\hline Pressure Inducer & CP 100, M/s KIMO & $\pm 1.5 \%$ & 0 to $100 \mathrm{~Pa}$ \\
\hline Thermal Image Camera & Ti 9, M/s Fluke & $\pm 5^{\circ} \mathrm{C}$ & $-20^{\circ} \mathrm{C}$ to $250^{\circ} \mathrm{C}$ \\
\hline Anemometer & Testo 425 & $\pm 0.03 \mathrm{~m} / \mathrm{s}$ & 0 to $20 \mathrm{~m} / \mathrm{s}$ \\
\hline Thermocouple & K-Type & $\pm 0.25 \%$ & 0 to $600^{\circ} \mathrm{C}$ \\
\hline
\end{tabular}

\section{IV.RESULTS AND DISCUSSION}

Analysis of Local heat transfer coefficient (h). To enhance the life and performance of a gas turbine, uniform and high heat transfer coefficients are desirable inside the cooling passages. However, achieving 100\% uniformity may not be possible due to the differences in pattern and strength of secondary flows generated by the ribs. Due to flow separation at the rib, heat transmission in the direction of the stream is mostly driven by the secondary flow. Heat transfer along the rib arms is controlled by the counter rotating vortices created by coolant flow along the arms. In general, characteristics like rib pitch, profile, angle-ofattack, and rib height determine the intensity of secondary flows. Heat transfer for isolated $\mathrm{V}$ and $\mathrm{W}$-ribs is presented in this section for the Re range 30000 - 75000. Figures 3-6 show the variations in rib configurations for span lengths of $0.25 \mathrm{w}$ and $0.5 \mathrm{w}$.

\section{Discrete V-ribs}

For the experimented range of Re, secondary flow is found to be dominant along the span $0.5 \mathrm{w}$ (centreline) and therefore the heat transfer coefficients for span length $0.5 \mathrm{w}$ are greater than $0.25 \mathrm{w}$. The magnitude of heat transfer coefficients between successive ribs varied along the stream and the variations for the experimented range of Re are comparable with the uncertainty estimated in measurement of Nusselt number. The phenomenon of heat transfer variation in the direction of stream is because of the growth of boundary layer which reduces the capacity of coolant to extract heat. Between the span lengths, the variation along $0.5 \mathrm{w}$ is found to be less than $0.25 \mathrm{w}$ due to sudden increase in velocity at the $3 \mathrm{~mm}$ gap between the rib arms. The acceleration at the gap is considered beneficial as it results to more uniform heat transfer than that observed for continuous V-ribs. The influence of acceleration on heat transfer is noticed even along $0.25 \mathrm{w}$ span length and the same is seen to be improving with Re. In addition, as the flow progressed, improvement in secondary flow is observed for all the Re which is speculated to be because of the increment in coolant momentum induced by the gap. In general, for the experimented range of Re, heat transfer in the side wall regions is observed to be lowest. With increase in $\mathrm{Re}$, heat transfer in the side wall regions improved. Averaged variations between highest and lowest heat transfer coefficients has been determined for the span lengths $0.25 \mathrm{w}$ and $0.5 \mathrm{w}$. At Re 30000 , the variations are found to be $11 \%$ and $9.5 \%$ along $0.25 \mathrm{w}$ and $0.5 \mathrm{w}$ respectively. For the Re 45000 and 60000, variations along $0.25 \mathrm{w}$ are seen to be $10 \%$ and $8.5 \%$. Along $0.5 \mathrm{w}$, the variations are $7.5 \%$ and $9 \%$ respectively. At Re 75000 , the variation is $9.5 \%$ along $0.25 \mathrm{w}$ and $8.5 \%$ along $0.5 \mathrm{w}$. To appreciate the effects of ribs better, the wall temperature distribution for the experimented Re range is depicted in figure 7 . For all the cases, the wall temperatures along the centreline and nearby regions are found to be less than other regions due to the collective effect of stronger secondary flow produced by the apex and the acceleration induced by the gap. Comparison of thermal plots reveals that, wall temperatures in the regions adjacent to the side walls are highest for Re 30000 due to weak secondary flow. Further, a reduction in difference between the maximum and minimum wall temperatures as a result of improvement in strength of secondary flow with $\mathrm{Re}$ is evident from the thermal contours.

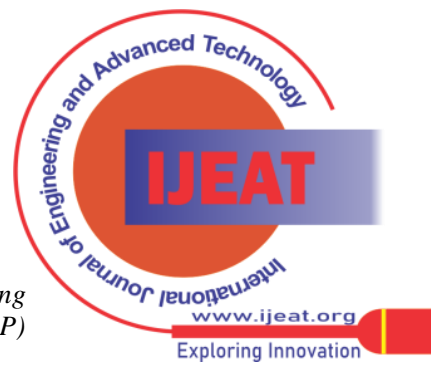




\section{Effect of Discrete Ribs on Heat Transfer and Friction Inside Narrow Rectangular Cross Section Cooling Passage (AR=1:5) of Gas Turbine Blade}

In addition, as the flow progressed, an increase in strength of secondary flow due to the increment in momentum can be well appreciated from the thermal contours corresponding to Re 30000, 45000 and 60000. The increment in strength along the flow is also observed at Re 75000 however, it is relatively lesser which is speculated to be as a result of reduction in coolant flow in the direction of stream due to flow diversion towards side walls.

\section{Discrete W-ribs}

For the experimented Re range, heat transfer in the span direction is uniform due to the effect of superior secondary flow produced by the two apexes of discrete $\mathrm{W}$-ribs. Akin to discrete V-ribs, intensity of heat transfer varied in stream direction for both the span lengths and the variation along $0.5 \mathrm{w}$ is found to be marginally lesser than $0.25 \mathrm{w}$ due to influence of discreteness. Average variation along the span lengths has been evaluated and it is seen that the variation is $16 \%$ for $0.25 \mathrm{w}$ and $15 \%$ for $0.5 \mathrm{w}$ at Re 30000 . For the Re 45000 and 60000 , variations for span length $0.25 \mathrm{w}$ are $21 \%$ and $25 \%$ respectively. For the span length $0.5 \mathrm{w}$, variations are $18 \%$ and $19 \%$ respectively. At Re 75000 , the variations for $0.25 \mathrm{w}$ and $0.5 \mathrm{w}$ span lengths are $19 \%$ and $17 \%$ respectively. From the above analysis, we can conclude that the presence of gap helps in achieving more uniform heat transfer which in turn will enhance the service life of the blade. Besides, we can also conclude that, variations along the span are likely to reduce further beyond Re 75000 due to the increase in coolant diversion owing to reduction in boundary layer thickness. As a result of diversion, coolant concentration along $0.5 \mathrm{w}$ and side wall regions increases suddenly which in turn leads to an improvement in uniformity. Wall temperature distribution is depicted in figure 8. In general, for the experimented $\mathrm{Re}$ range, difference in wall temperatures along the span is found to be negligible indicative of uniform hear transfer. Comparison of thermal plots reveals that, average wall temperature is highest for Re 30000 and hence the heat transfer is lowest. In addition, the reduction in average wall temperature for an increase in Re can be appreciated from the thermal contours. The influence of $3 \mathrm{~mm}$ gap between the rib arms on heat transfer is present however, it is less prominent in comparison to discrete V-ribs. For Re 75000, patches of very low wall temperatures are seen in the regions adjacent to $0.5 \mathrm{w}$, which is not seen for other Re. This is speculated to be as a result of sudden increase in coolant momentum along the centreline due to the influx of diverted coolant.

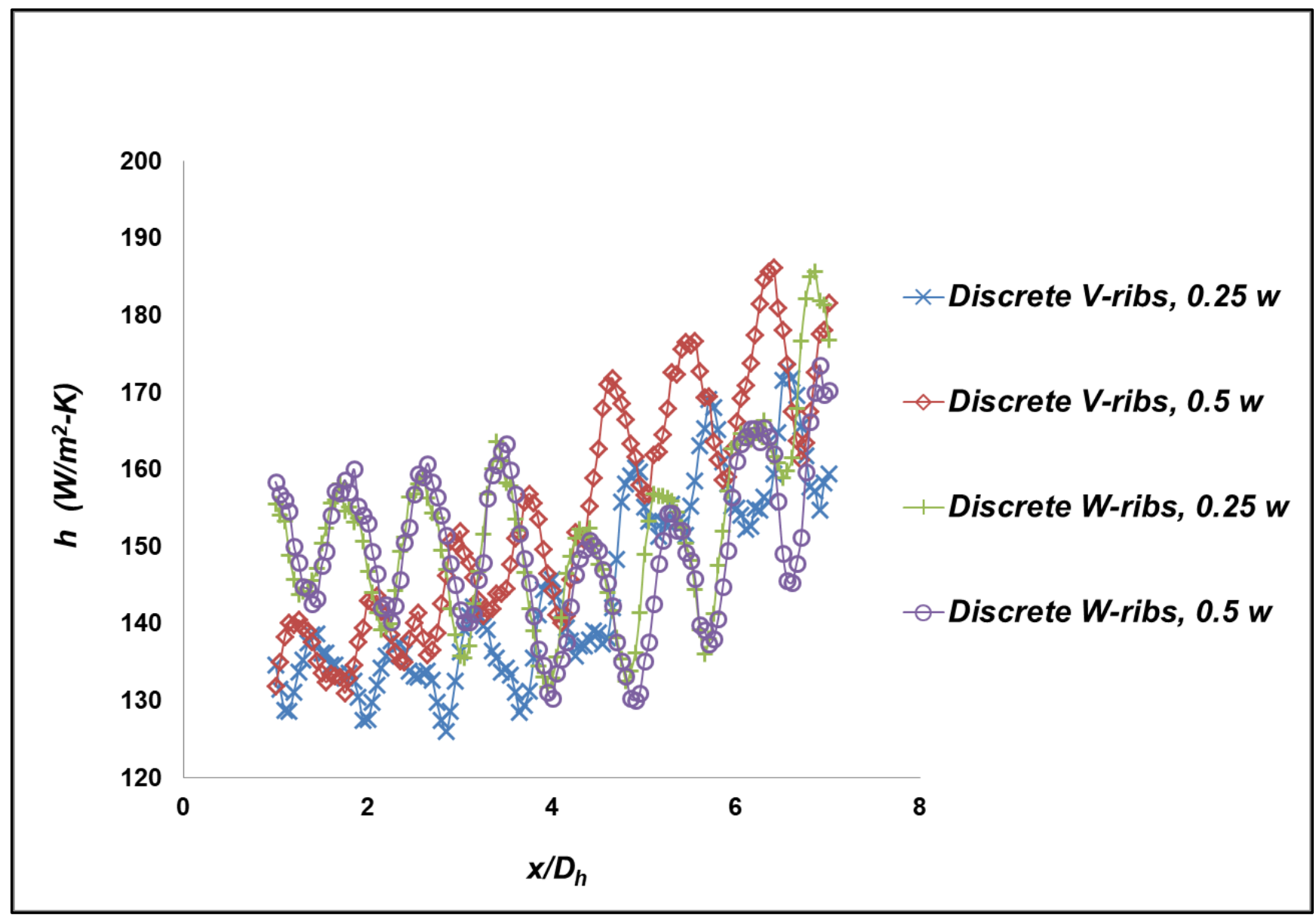

Fig.3 Heat transfer coefficient $(h)$ along the stream for $R e 30000$

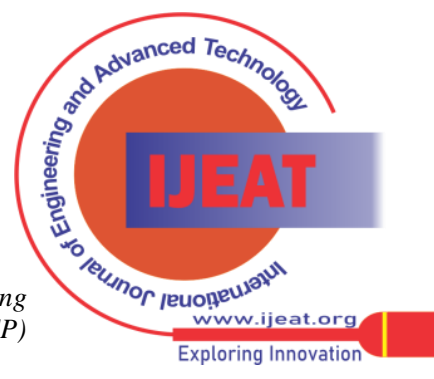




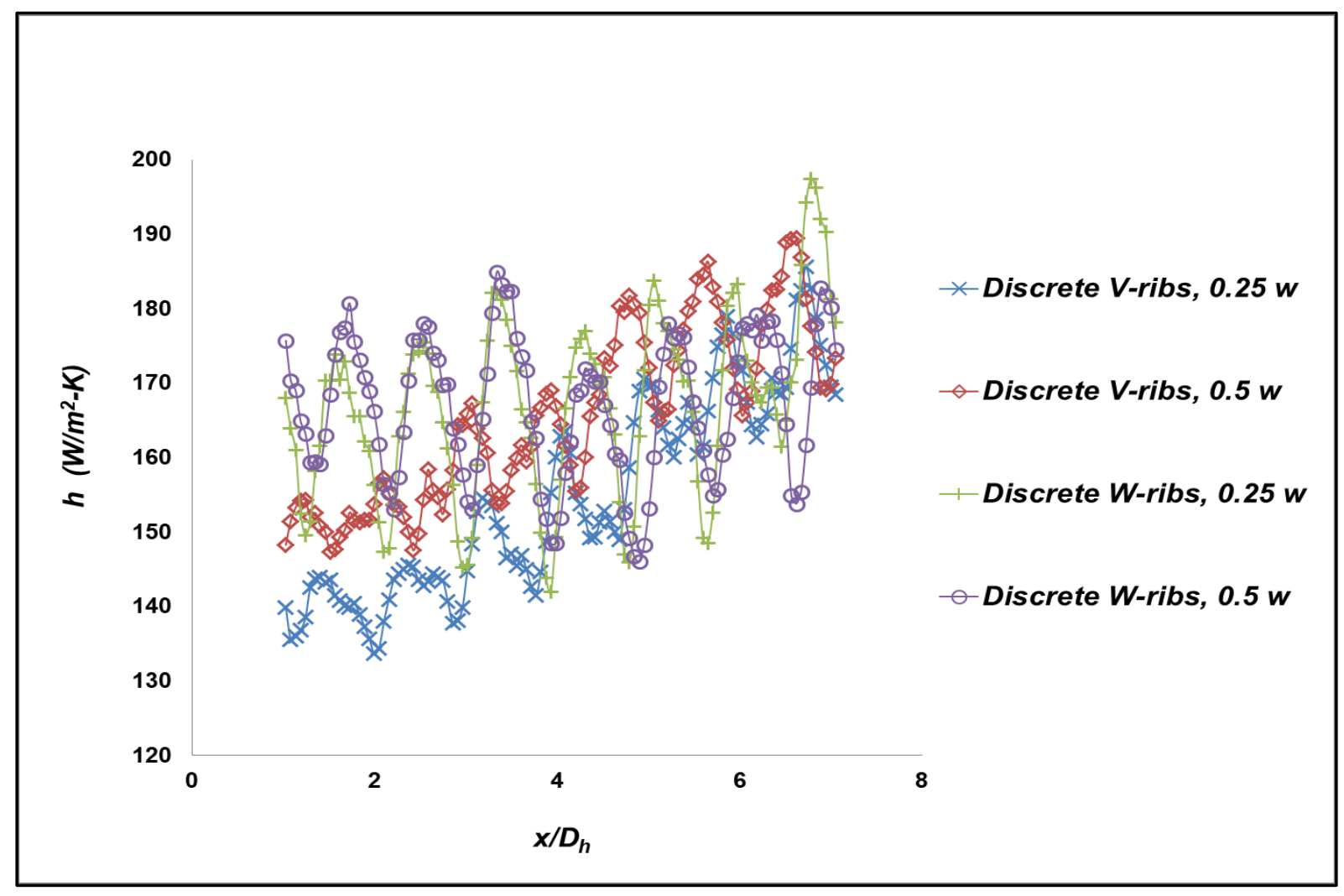

Fig.4 Heat transfer coefficient (h) along the stream for $\operatorname{Re} 45000$

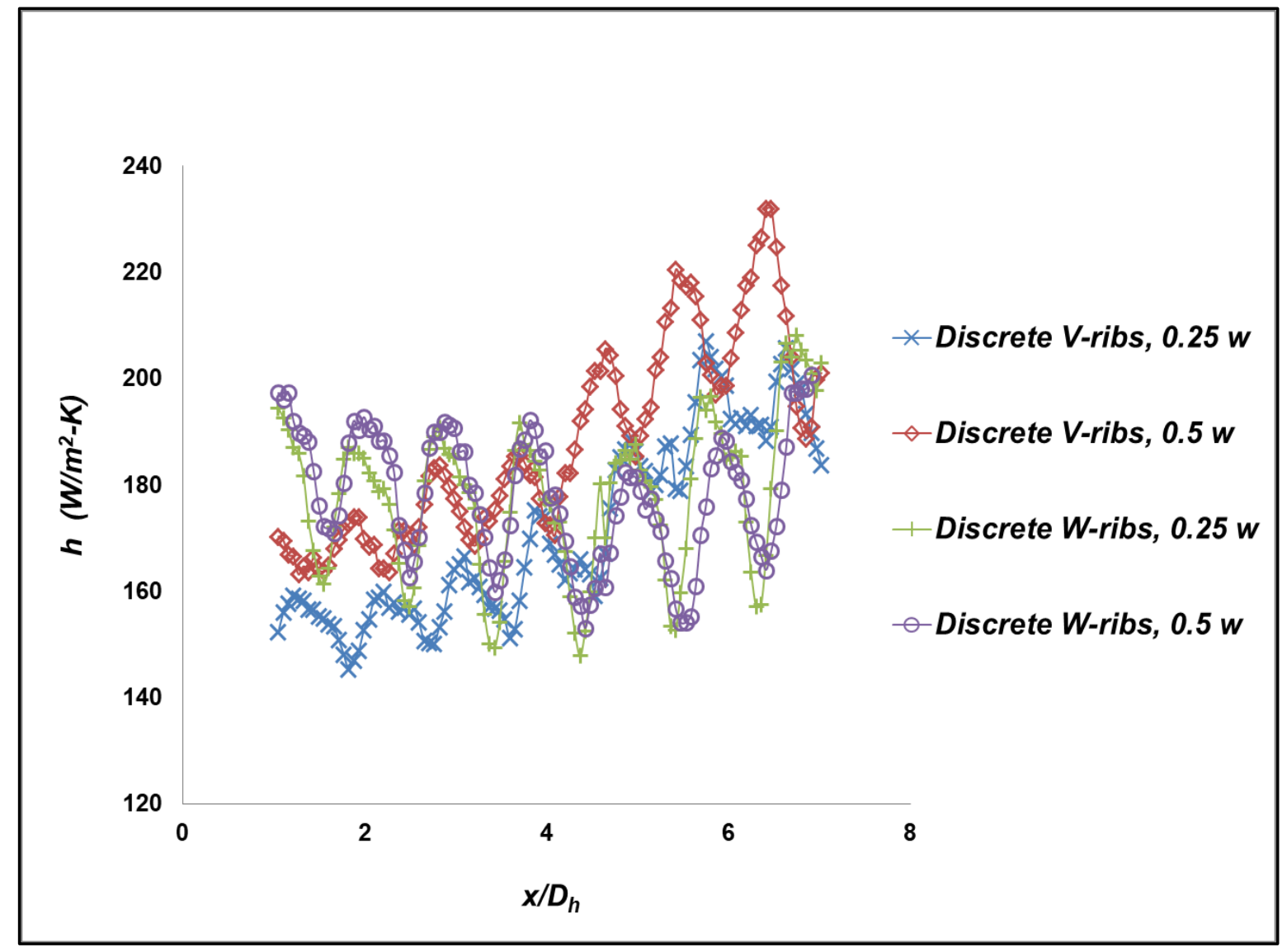

Fig.5 Heat transfer coefficient $(h)$ along the stream for $\operatorname{Re} 60000$

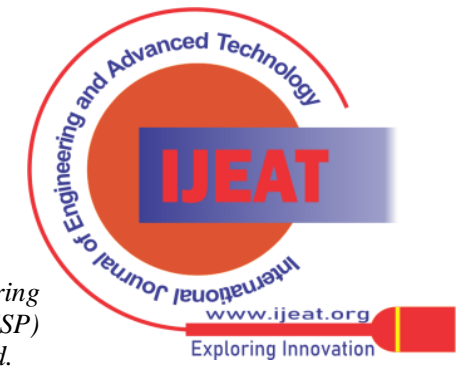


Effect of Discrete Ribs on Heat Transfer and Friction Inside Narrow Rectangular Cross Section Cooling Passage (AR=1:5) of Gas Turbine Blade

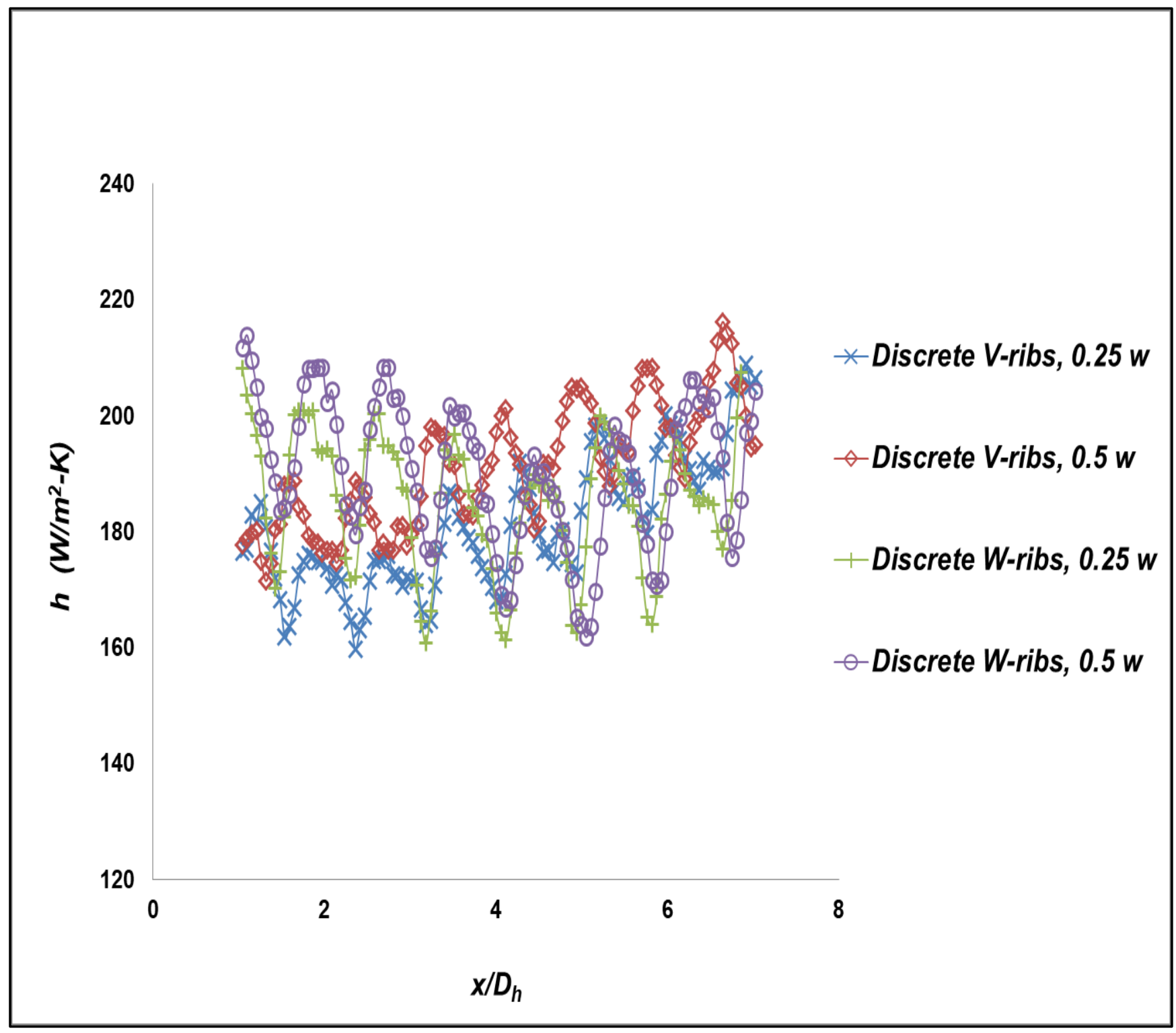

Fig.6 Heat transfer coefficient $(h)$ along the stream for $\operatorname{Re} 75000$
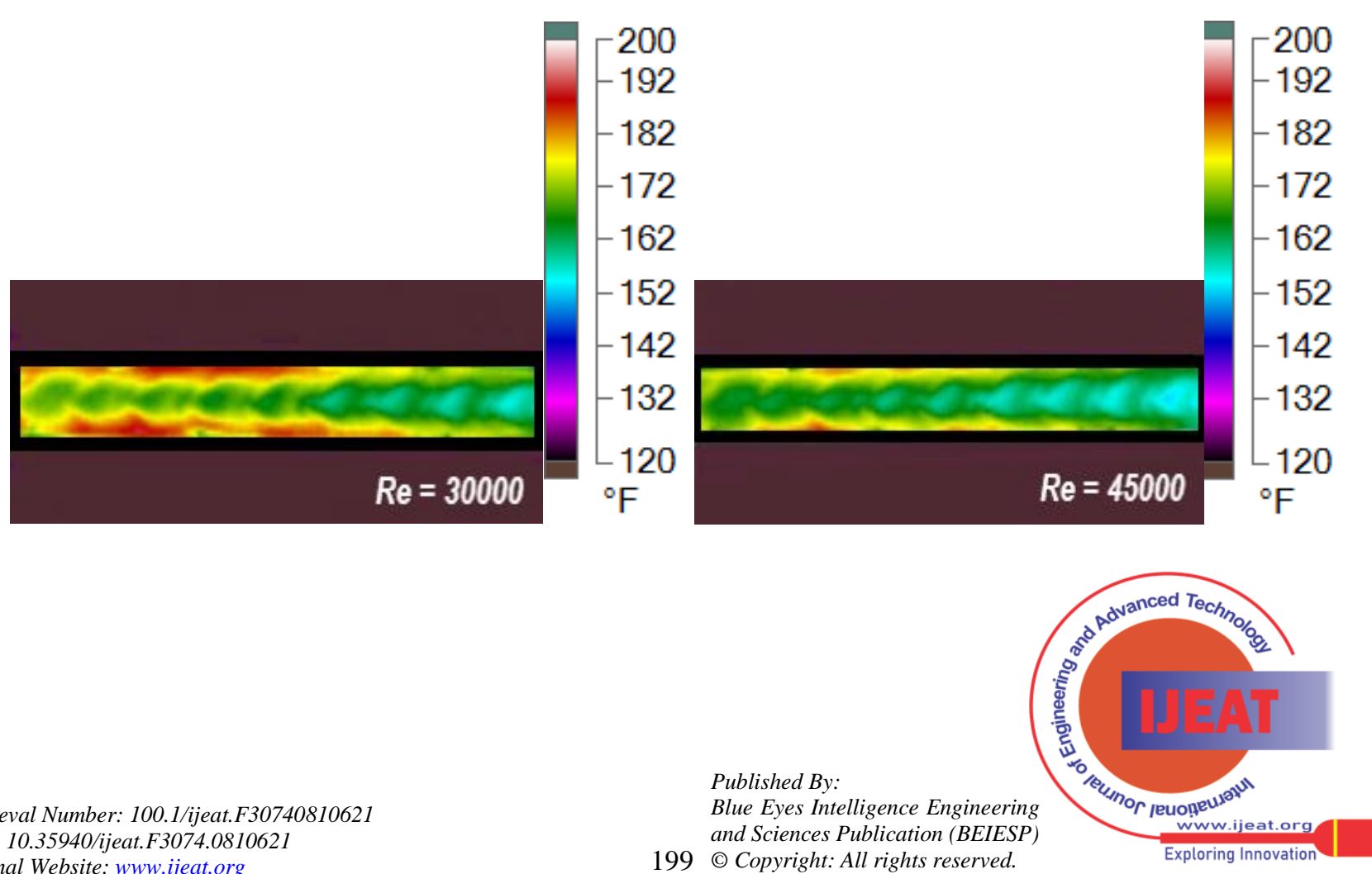


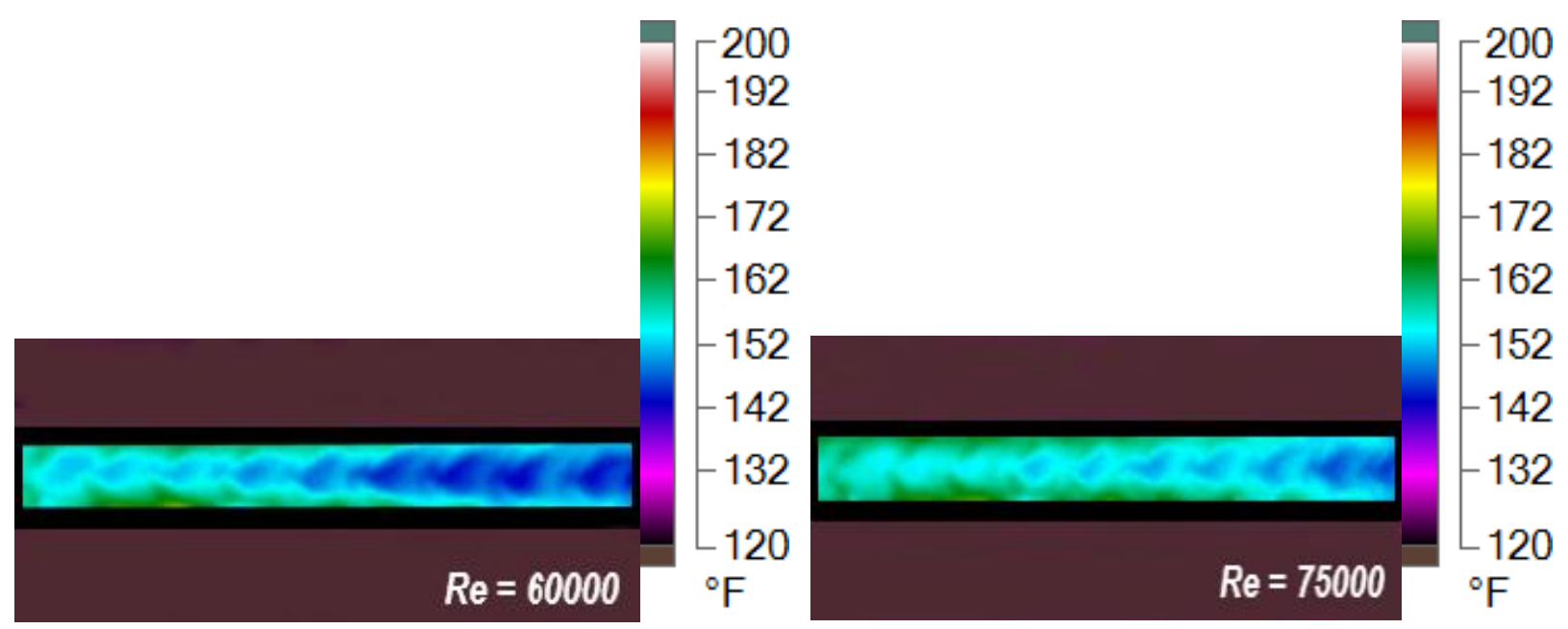

Fig.7 Thermal plots of discrete V-ribs for experimented $R e$ range
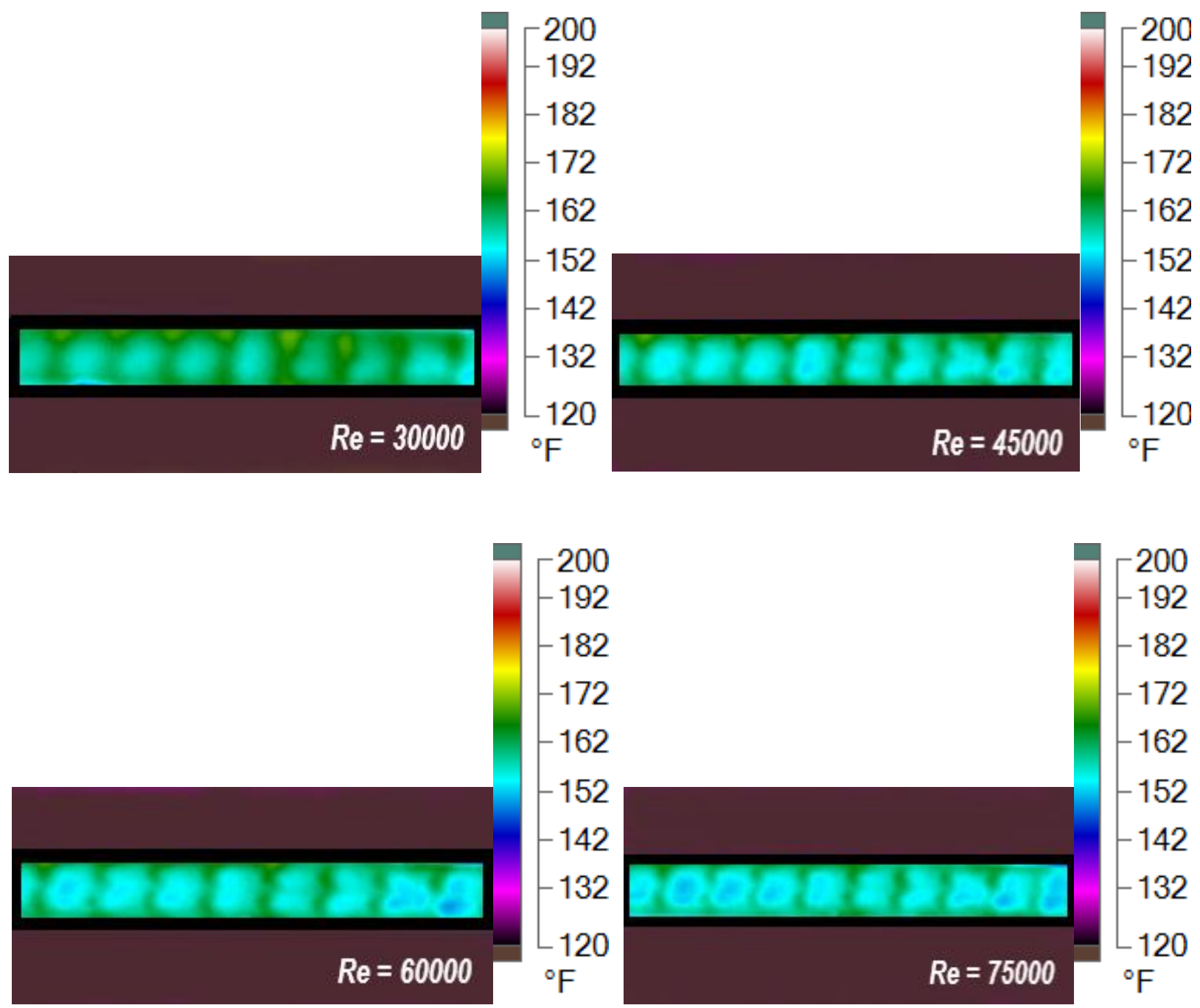

Fig.8 Thermal plots of discrete $\mathrm{W}$-ribs for experimented $R \boldsymbol{R}$ range

Span averaged heat transfer coefficient $\left(h_{\text {avg }}\right)$. Figure 9 shows $h_{\text {avg }}$ corresponding to the investigated Reynolds numbers. For discrete V-ribs, averaged values estimated along $0.5 \mathrm{w}$ are $6-8 \%$ higher than that estimated along 0.25 $w$. As the $R e$ increased, $h_{\text {avg }}$ also increased. Maximum increment of $11.5 \%$ is observed with increase in $R e$ from 45000 to 60000 . Between the $R e 30000$ and 45000, heat transfer increment is $7 \%$ and between the $R e 60000$ and 75000 , the increment is $5 \%$. Beyond $R e$ 60000, the enhancement is seen reducing in the direction of flow, because of coolant diversion owing to reduction in velocity boundary layer thickness.

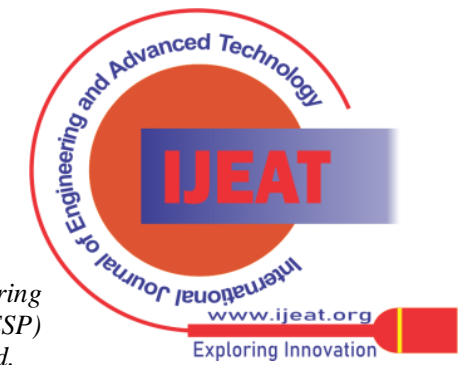




\section{Effect of Discrete Ribs on Heat Transfer and Friction Inside Narrow Rectangular Cross Section Cooling Passage (AR=1:5) of Gas Turbine Blade}

In general, it is noticed that, enhancement in heat transfer achieved between successive $R e$ for discrete V-ribs are relatively lesser than the enhancements presented in literature for continuous V-ribs. From the results we can conclude that, discrete V-ribs in comparison to continuous V-ribs aid in achieving more uniform heat transfer for relatively lesser enhancements. Also, overall heat transfer augmentation in the direction of stream beyond $R e 75000$ is expected to reduce further because of coolant diversion. While the heat transfer along the stream may not be appreciable, the diversion of coolant will enhance the intensity of vortices along rib arms, which consecutively will augment the heat transfer in side wall and near-rib regions. In the case of discrete $\mathrm{W}$-ribs, enhancements achieved for the span lengths $0.25 \mathrm{w}$ and $0.5 \mathrm{w}$ are comparable with a maximum difference of $2.5 \%$ at $R e$ 75000. Akin to discrete V-ribs, for an increase in $R e, h_{\text {avg }}$ increased and the increase between successive $R e$ is observed to be approximately $9.5 \%$ for $R e$ up to 60000 . Between the $\operatorname{Re} 60000$ and 75000, increase in enhancement is lowest and is calculated to be $2 \%$ along $0.25 \mathrm{w}$ and $6 \%$ along $0.5 \mathrm{w}$. The coolant diverted from the apex augmented the strength of secondary flow along span length $0.5 \mathrm{w}$ and therefore the enhancement along $0.5 \mathrm{w}$ is relatively higher than $0.25 \mathrm{w}$. Similar to V-ribs, coolant diversion along the rib arms due to low velocity boundary layer thickness is considered as the primary reason for reduction in overall enhancement at $R e 75000$. From the results we can conclude that, discrete $\mathrm{W}$-ribs in comparison to continuous $\mathrm{W}$-ribs aid in achieving more uniform heat transfer for relatively lesser enhancements. Besides, overall augmentation in heat transfer in the direction of stream after $R e 75000$ is likely to drop further as a result of diversion of coolant away from the stream.

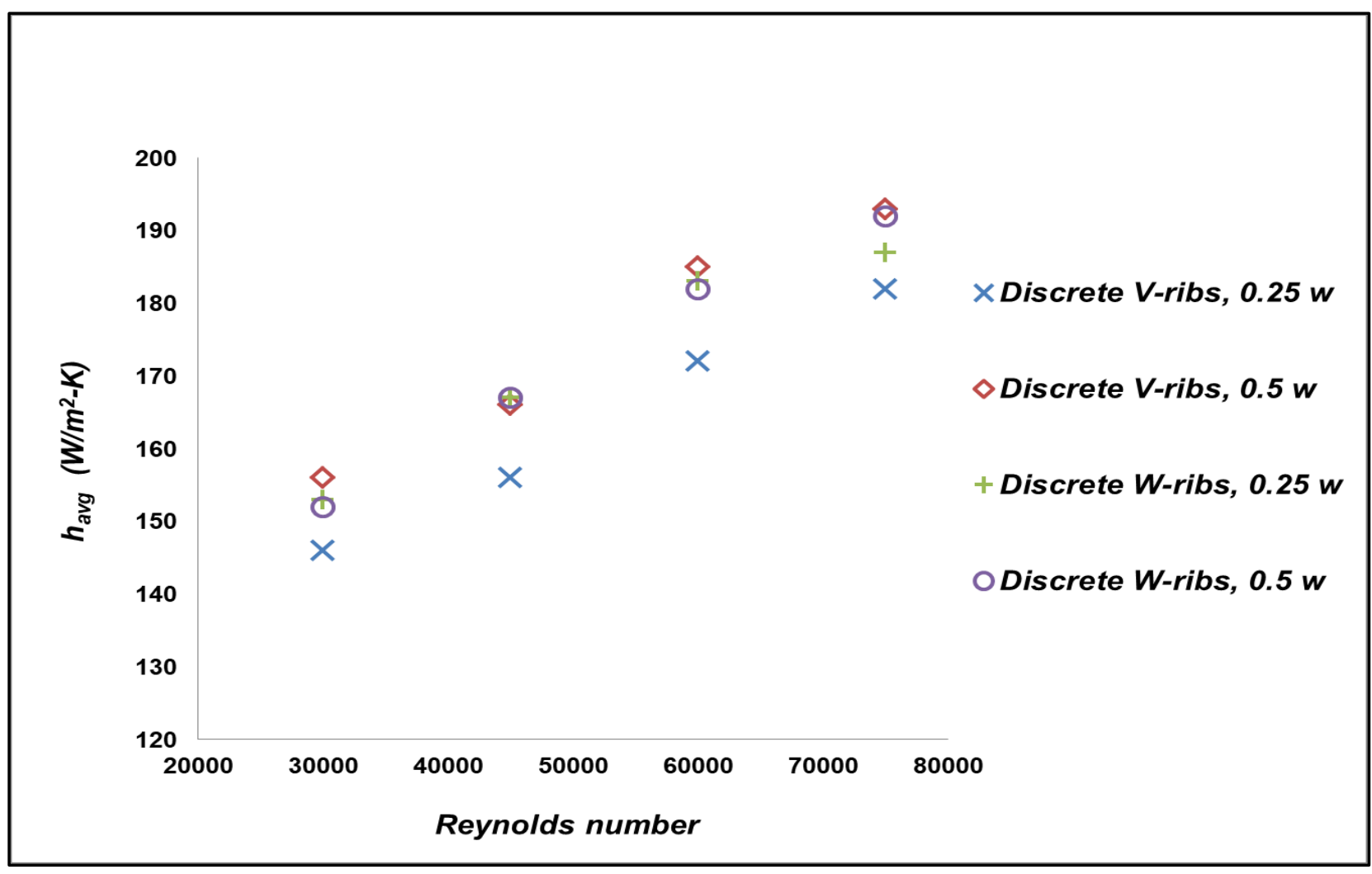

Fig.9 Span averaged heat transfer coefficient $\left(h_{\text {avg }}\right)$ for investigated $R e$ range

Area averaged Nusselt number ratio. The area averaged Nusselt number ratio $(\mathrm{Nu} / \mathrm{Nuo})$ for the rib profiles is shown in Figure 10. As the Re grew, the Nu/Nuo for the rib profiles decreased. Values of 3.4 and 2 are recorded for discrete V-ribs, corresponding to $\operatorname{Re} 30000$ and 75000, respectively. The $\mathrm{Nu} / \mathrm{Nuo}$ is expected to be 2.7 at $\mathrm{Re} 45000$ and 2.3 at Re 60000 . Nu/Nuo values for discrete $\mathrm{W}$-ribs are calculated to be 3.6 and 2.1 for $\operatorname{Re} 30000$ and 75000, respectively. The values for the Re 45000 and 60000 are 2.8 and 2.4, respectively. $\mathrm{Nu} / \mathrm{Nuo}$ is discovered to be high for both rib profiles, which is attributed to the larger strength of secondary flows created by the ribs inside the narrow cooling passage. High and uniform heat transfer augmentations are desired to improve an engine's power and performance, and the discrete $\mathrm{V}$ and $\mathrm{W}$-ribs assessed in this study are recommended for deployment in places subjected to harsh temperatures. The Nusselt number ratios (Nu/Nus) for the rib profiles are shown in Figure 11. Nu/Nus values are fewer than $\mathrm{Nu} / \mathrm{Nuo}$ values for the investigated range of Re. The Nu/Nus values estimated for discrete V-ribs and discrete W-ribs at Re 30000 are 2.7 and 2.9 respectively. For Re 75000, Nu/Nus for discrete V-ribs and discrete W-ribs are 1.8 and 1.9 respectively. 


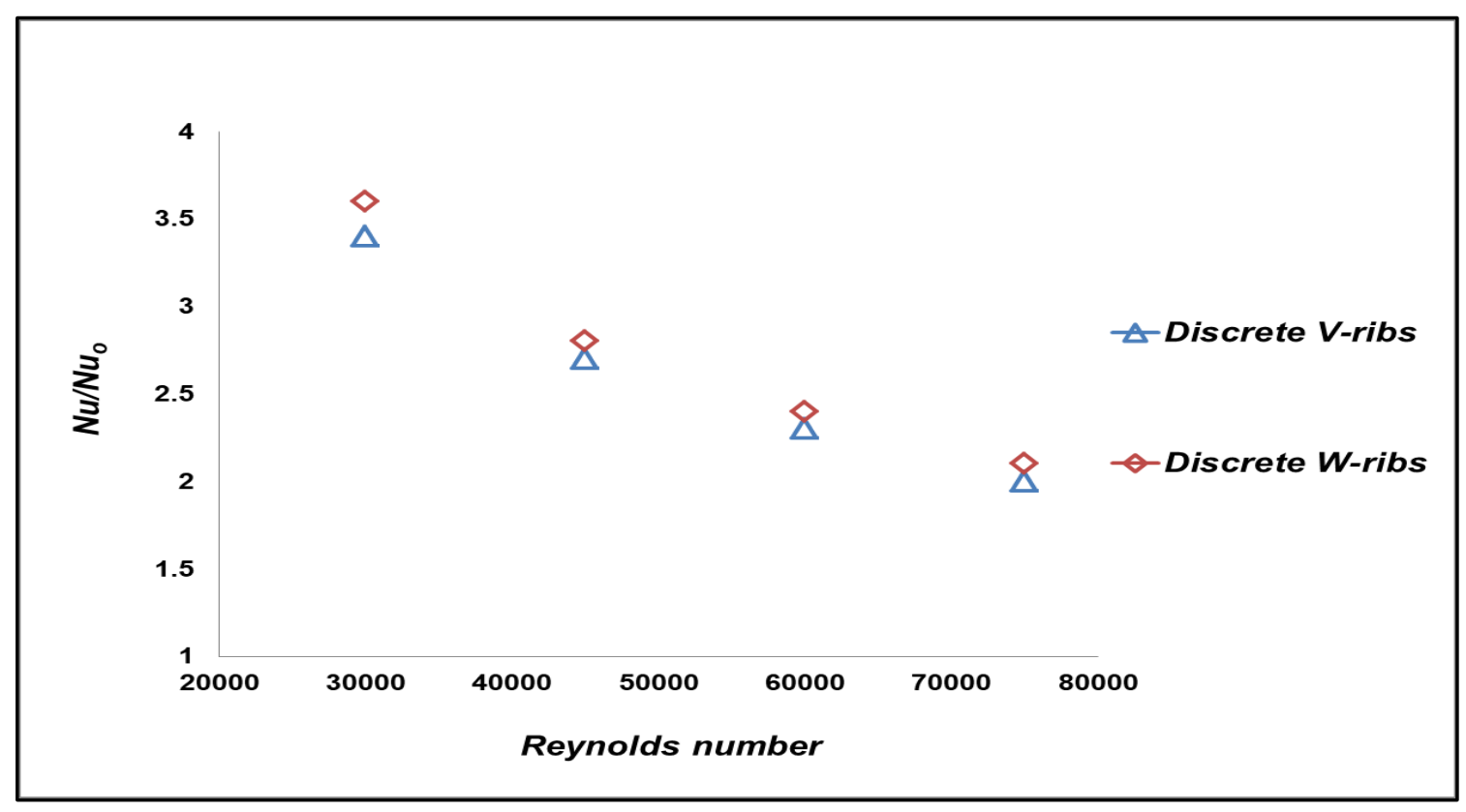

Fig.10 Area averaged Nusselt number ratio $(\mathrm{Nu} / \mathrm{Nu})$

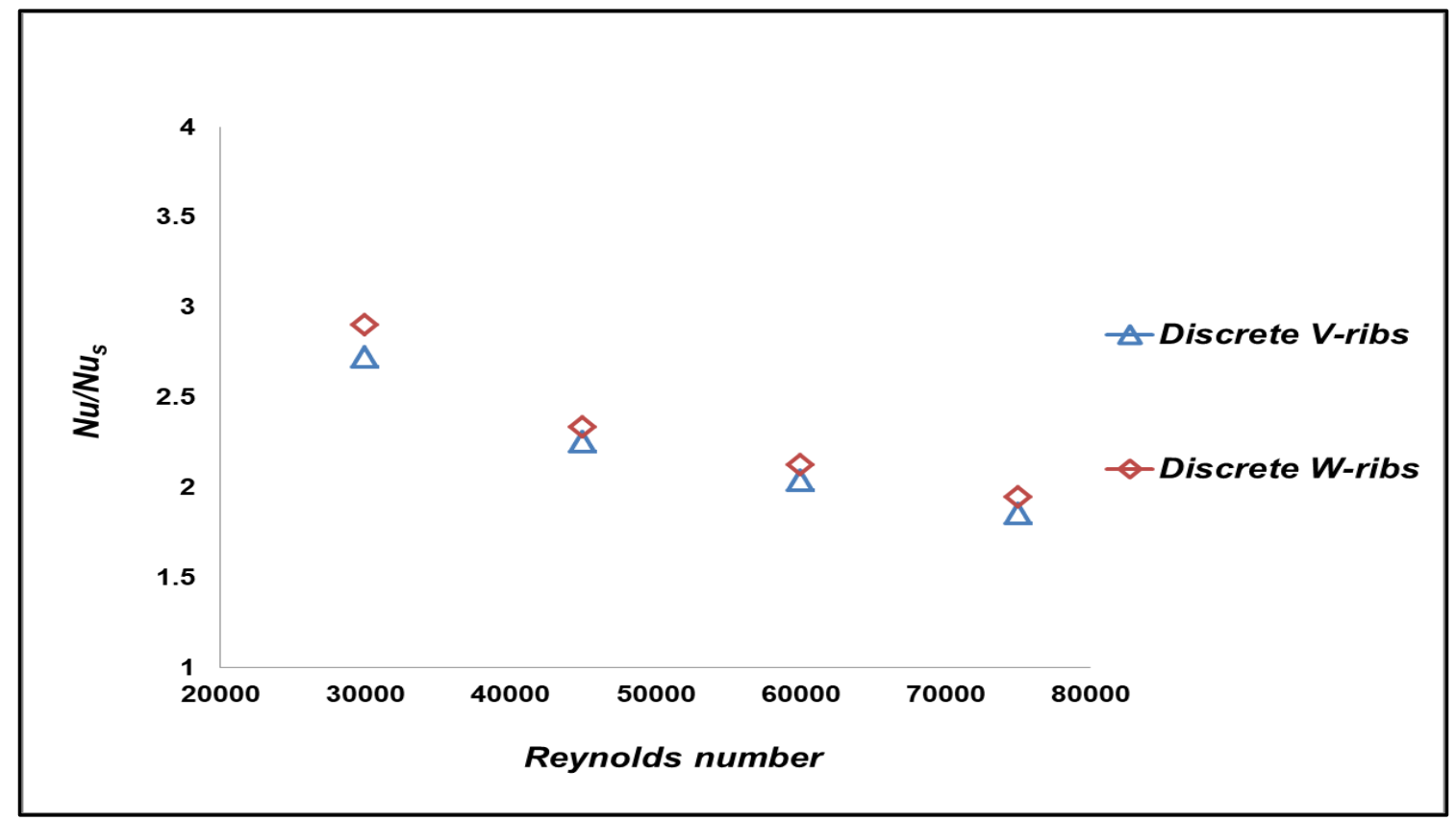

Fig.11 Area averaged Nusselt number ratio $(\mathrm{Nu} / \mathrm{Nu})$

Normalized Friction factor. The magnitude of friction loss inside a ribbed cooling tunnel is mostly determined by the pressure drop caused by the ribs. The friction factor ratio (f/fo) for the rib profiles is shown in Figure 12. Friction factor ratios for discrete V-ribs range from 1.2 to 1.7 for the Re range studied. Between consecutive Re, maximum pressure drop increment of $17 \%$ is observed between the Re 30000 and 45000. Subsequently, increment is seen to be $14 \%$ between the Re 45000 and 60000 and $6 \%$ between the $\operatorname{Re} 60000$ and 75000 . Appreciable reduction in $\mathrm{f} / \mathrm{fo}$ increment between the $\mathrm{Re}$ 60000 and 75000 is because of the occurrence of coolant diversion towards side walls, which eventually led to a reduction in overall pressure drop. For discrete W-ribs, values corresponding to the experimented Re are observed to be ranging from 1.6-2. For Re up to 60000, pressure drop increment between successive Re is noticed to be the same

at 6\%. Between Re 60000 and 75000, one would anticipate a drop in increment due to the diversion of coolant. However, in the contrary, increase in pressure drop is seen to be highest at Re 75000 , which resulted to a difference of $11 \%$ between the friction factor ratios. The increase is attributed to the sudden rise in coolant concentration along span length $0.5 \mathrm{w}$ due to diversion, which eventually resulted to an appreciable increase in pressure drop. Despite having the same blockage ratio and pitch, it can be seen that, pressure drop generated by the discrete $\mathrm{W}$-ribs are higher than discrete V-ribs due to the combined effect of low angle-of-attack and large contact area.

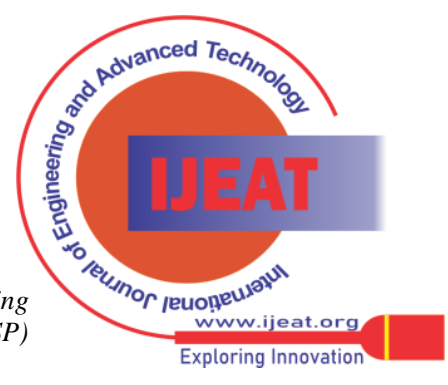




\section{Effect of Discrete Ribs on Heat Transfer and Friction Inside Narrow Rectangular Cross Section Cooling Passage (AR=1:5) of Gas Turbine Blade}

Figure 13 presents the friction factor ratio (f/fs) for discrete $\mathrm{V}$ and $\mathrm{W}$-ribs. As expected, for the range of Re studied, $\mathrm{f} / \mathrm{fs}$ of discrete $\mathrm{W}$-ribs are noticed to be higher than that of discrete V-ribs. Comparison of smooth wall friction (fs) with predicted friction (fo) reveals that the smooth wall friction is lesser than predicted friction. This may be because the flow is streamlined inside the test section with
$\mathrm{AR}=1: 5$ due to the large gap between the walls. For the Re range 30000 and 75000 , differences noticed between friction factors fs and fo are nearly $5 \%$ and $21 \%$. As the friction losses are observed to be low inside the aspect ratio 1:5 channel, higher blockage ratio ribs can be deployed to achieve higher enhancements with no major effect on friction loss.

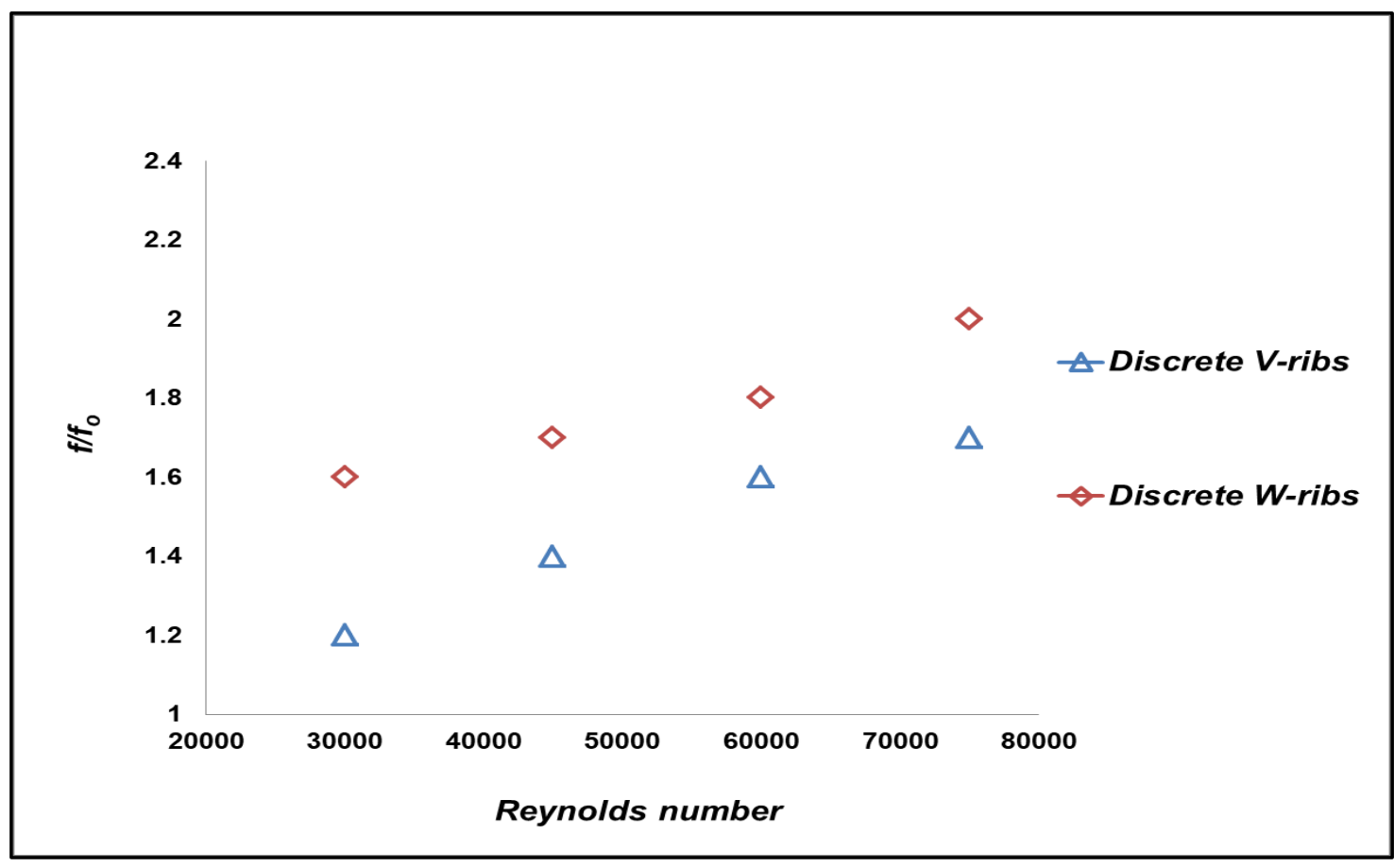

Fig.12 Normalized friction factor $\left(f / f_{o}\right)$ for investigated range of $R e$

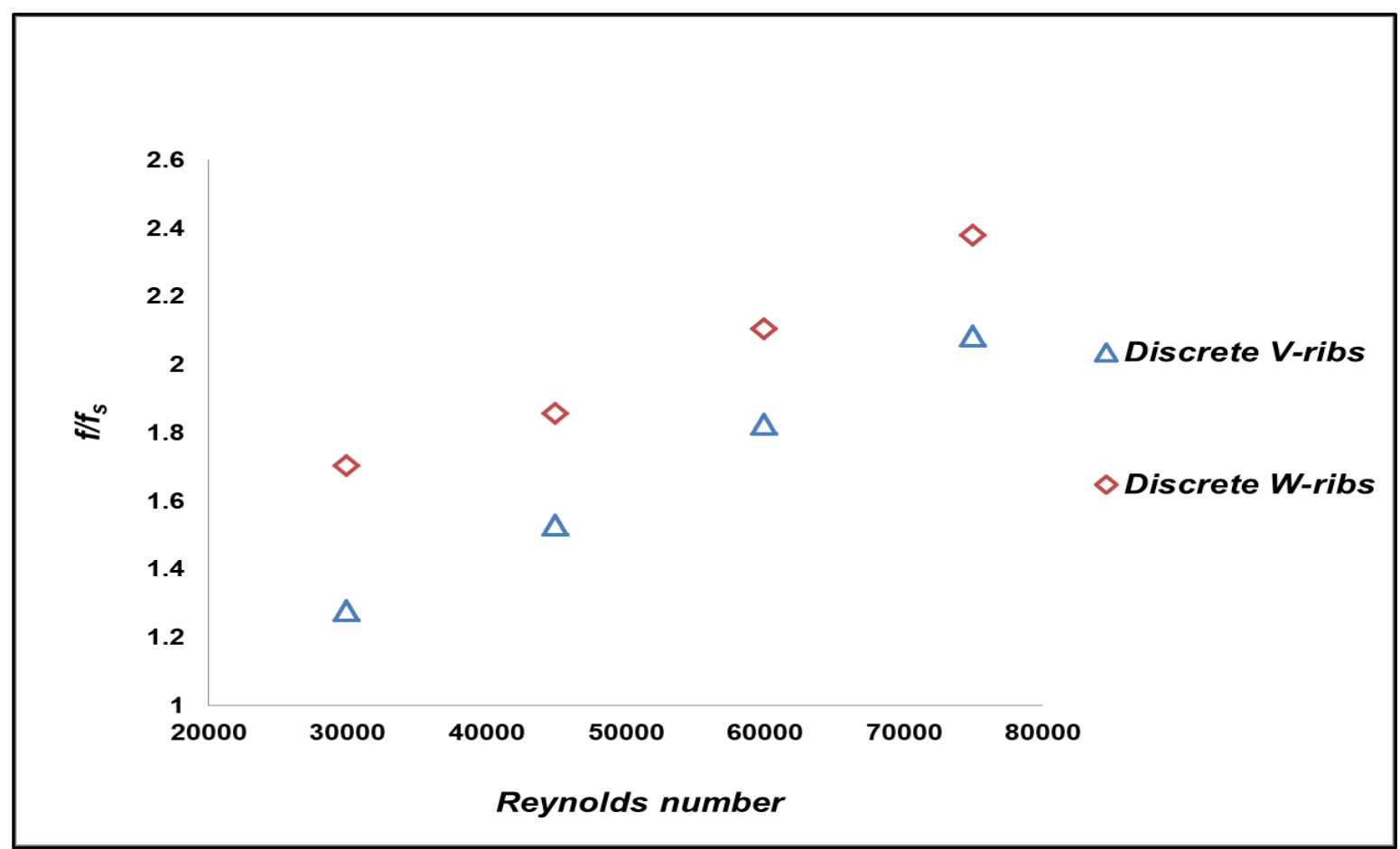

Fig.13 Normalized friction factor $\left(f / f_{s}\right)$ for investigated range of $R e$

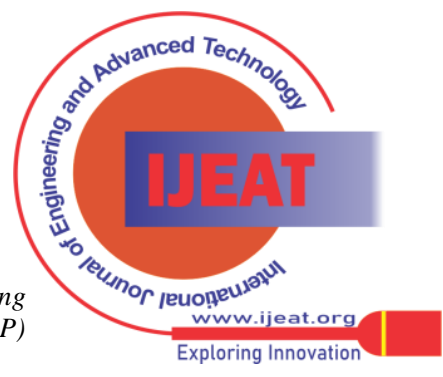


Thermohydraulic Performance. Figure 14 shows the Thermohydraulic Performance (THPo) values for the Re range investigated. For discrete V-ribs, THPo values corresponding to the maximum and minimum $\mathrm{Re}$ experimented are 3.2 and 1.7. For Re 45000 and 60000, the values are 2.4 and 2. Analysis reveals that, reduction is highest at 33\% between $\operatorname{Re} 30000$ and 45000. This is because, reduction in $\mathrm{Nu} / \mathrm{Nuo}$ is relatively higher than the reduction noticed in f/fo between Re 30000 and 45000. For discrete $\mathrm{W}$-ribs, maximum and minimum thermohydraulic performances for Re 30000 and 75000 are 3 and 1.65. The
THPo values estimated for Re 45000 and 60000 are 2.3 and 1.95. Similar to discrete V-ribs, between Re 30000 and 45000 , reduction in $\mathrm{Nu} / \mathrm{Nuo}$ is comparatively greater than the reduction noticed in $\mathrm{f} / \mathrm{fo}$ and therefore the reduction in THPo is highest at $30 \%$ in this range of Re. Figure 15 depicts the Thermohydraulic Performance (THPs) values for the experimented Re. The THPs of discrete V and W-ribs are estimated to be lesser than THPo. Corresponding to Re 30000 and 75000, THPs values for discrete V-ribs are estimated as 2.6 and 1.5 respectively. For discrete W-ribs, the estimated values are 2.4 and 1.5 .

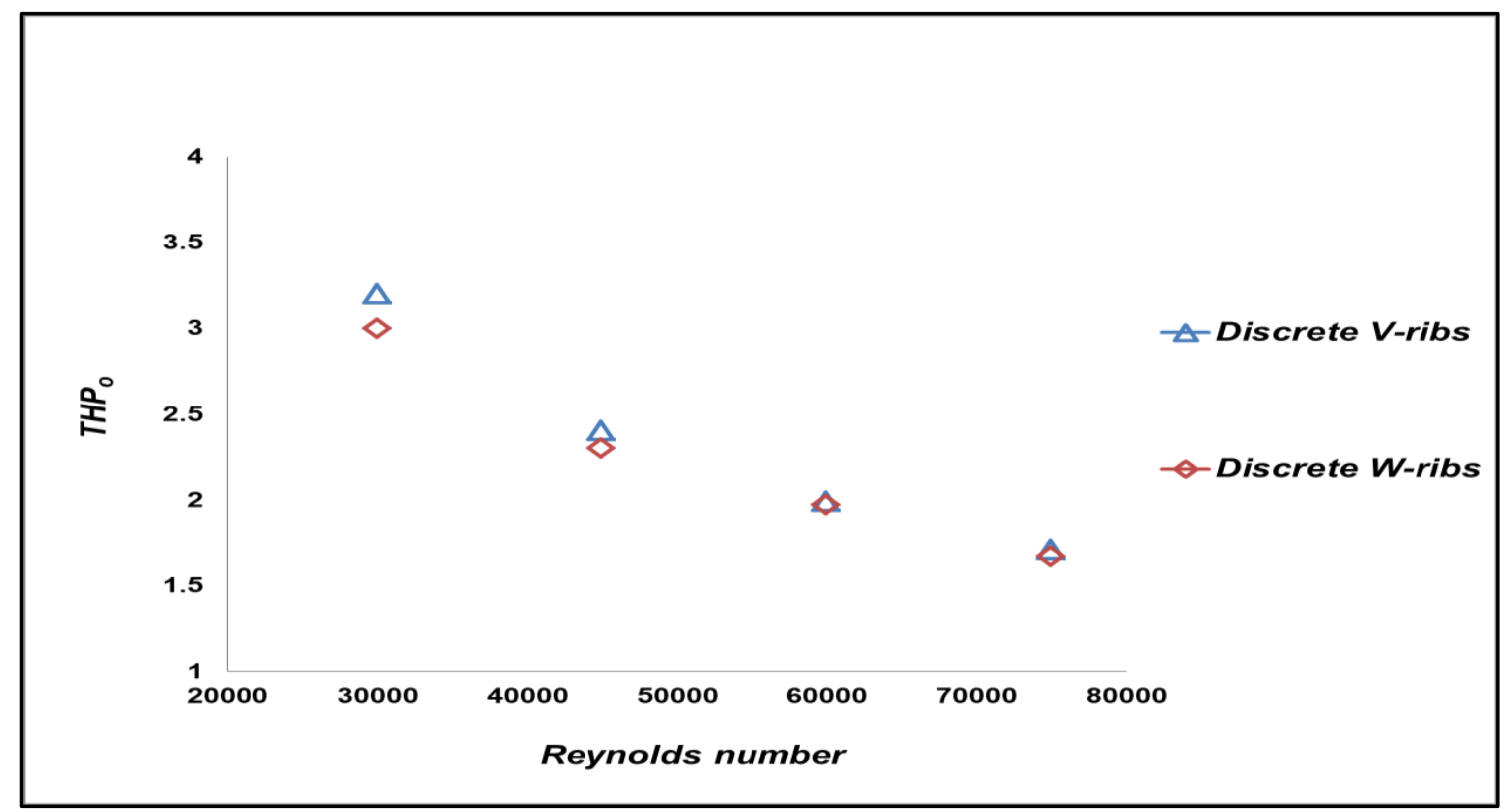

Fig.14 Thermohydraulic Performance (THPo) of both ribs for investigated range of $R e$

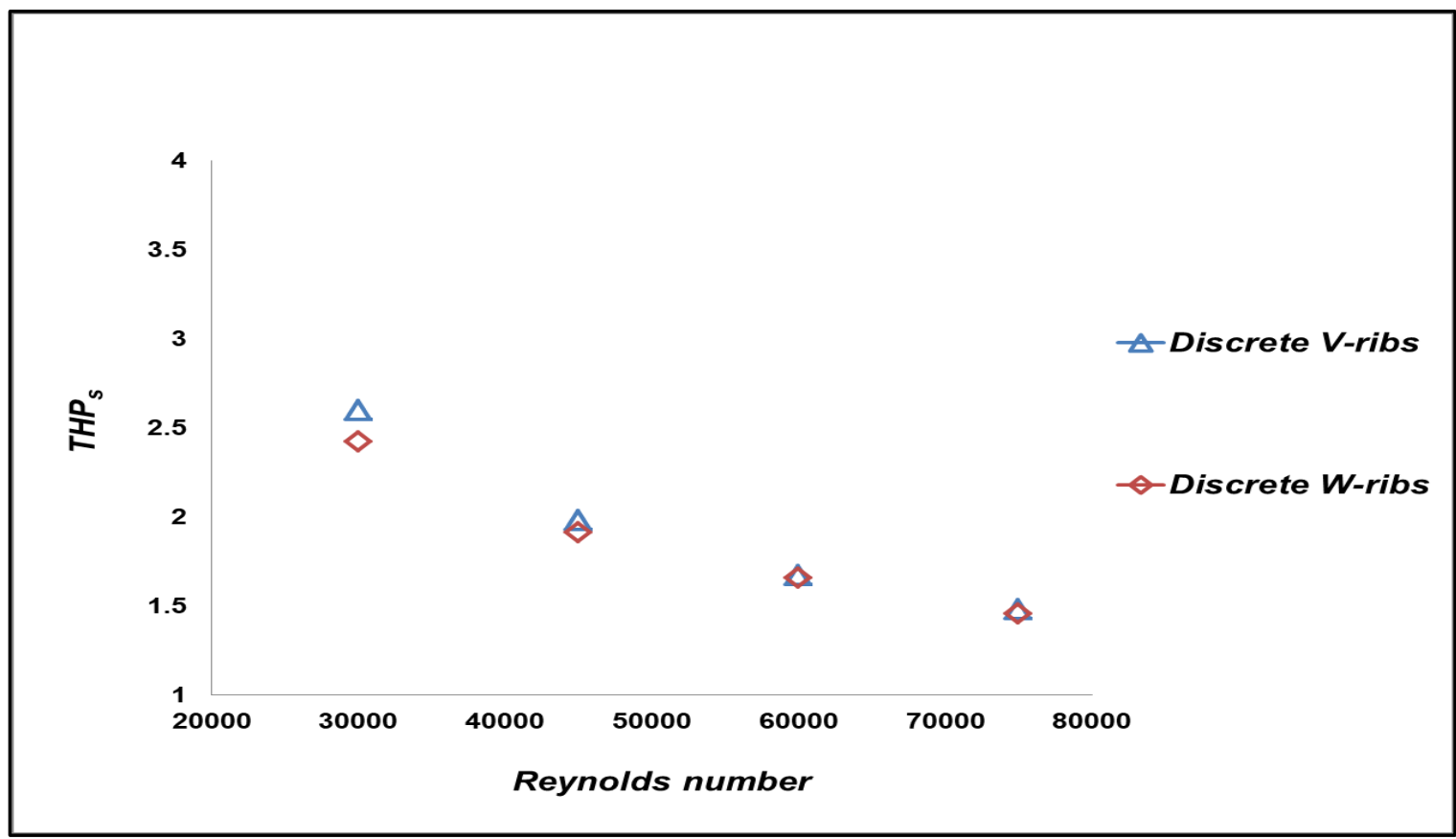

Fig.15 Thermohydraulic Performance $\left(T H P_{s}\right)$ of both ribs for investigated range of $R e$

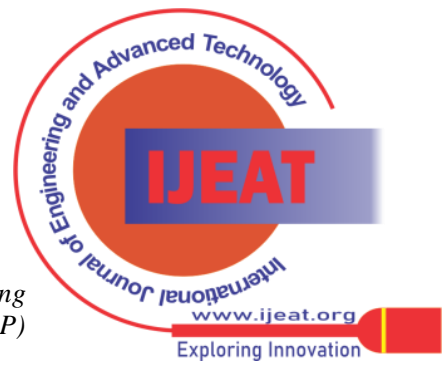




\section{Effect of Discrete Ribs on Heat Transfer and Friction Inside Narrow Rectangular Cross Section Cooling Passage ( $A R=1: 5)$ of Gas Turbine Blade}

Comparative Study.

Table 3 and figure 16 shows the $\mathrm{Nu} / \mathrm{Nuo}$ values of the present and published studies. The $\mathrm{Nu} / \mathrm{Nuo}$ value for discrete $\mathrm{V}$-ribs $(\mathrm{e} / \mathrm{Dh}=0.06)$ corresponding to Re 30000 is $10 \%$ higher than broken $\mathrm{V}$ ribs (e/Dh=0.0625) inside an aspect ratio 1:1 channel studied by Han and Zhang [3]. However, at Re 45000, value is found to be equal and for Re 60000 and 75000, Nu/Nuo values reported by Han and Zhang [3] are higher than the present findings. $\mathrm{Nu} / \mathrm{Nuo}$ ratios for discrete $\mathrm{V}$-ribs with blockage ratio 0.06 are 15-17 percent higher for Re 30000 and 60000 when compared to Ekkad and Han's results for broken $\mathrm{V}$-ribs (e/Dh=0.125) inside an aspect ratio 1:1 channel [4]. When compared to Wright et al. [7]'s Nu/Nuo value for discrete $\mathrm{V}$-ribs $(\mathrm{e} / \mathrm{Dh}=0.078)$ in a channel with an aspect ratio of $4: 1$, discrete $\mathrm{V}$-ribs employed in this study generated an 8 percent higher enhancement at Re 30000. Fu et al. [9] discovered that the enhancement recorded for $45^{\circ}$ ribs $(\mathrm{e} / \mathrm{Dh}=0.078)$ in an aspect ratio $1: 4$ channel is $26 \%$ less than the enhancement calculated at Re 30000 for discrete Vribs. Furthermore, the Nu/Nuo value for discrete V-ribs at Re 30000 is $13 \%$ higher than that predicted by Prashant et al. [22] in an aspect ratio 1:1 channel for continuous V-ribs (e/Dh=0.125). At Re 60000, the Nu/Nuo value estimated by Prashant et al. [22] is calculated to be $13 \%$ higher than the enhancement achieved for discrete V-ribs. In comparison to results presented by Krishnaswamy and Sivan [25] for continuous V-ribs (e/Dh=0.0729), the enhancements generated by discrete $\mathrm{V}$-ribs with $21.5 \%$ less blockage ratio are seen to be lesser by $17-26 \%$. The $\mathrm{Nu} / \mathrm{Nuo}$ values of discrete $\mathrm{W}$-ribs, like those of discrete $\mathrm{V}$-ribs, are found to be greater than those reported in the literature. When compared to the enhancement anticipated by Wright et al. [7] for discrete $\mathrm{W}$-ribs (e/Dh=0.078) inside an aspect ratio 4:1 channel at $\operatorname{Re} 30000$, the current work finds that enhancement owing to discrete $\mathrm{W}$-ribs $(\mathrm{e} / \mathrm{Dh}=0.06)$ is 6 percent higher. Furthermore, Nu/Nuo values estimated for discrete $\mathrm{W}$-ribs in our work are 44 percent and 14 percent greater than those predicted by Prashant et al. [22] for continuous W-ribs for the $\operatorname{Re} 30000$ and 60000 . Furthermore, discrete $\mathrm{W}$-rib improvements are shown to be 17-24 percent lower than those reported by Krishnaswamy and Sivan [25] for continuous W-ribs (e/Dh=0.0833). The enhancement owing to discrete $\mathrm{W}$-ribs at $\mathrm{Re} 30000$ is noticed to be 33 percent larger than the enhancement predicted by $\mathrm{Fu}$ et al. [9] for $45^{\circ}$ ribs (e/Dh=0.078) in an aspect ratio 1:4 channel. THPo values of discrete V-ribs and discrete W-ribs have been evaluated with different rib designs, as shown in table 4 and figure 17 . The THPo values of discrete $\mathrm{V}$ and $\mathrm{W}$-ribs inside cooling channels with aspect ratios of $4: 1,1: 6$, and $1: 1$ are 55 percent to 120 percent higher than those provided for other rib designs such as discrete V-ribs, discrete $\mathrm{W}$-ribs, angled and continuous ribs. Furthermore, the THPo values of discrete $\mathrm{V}$ and $\mathrm{W}$-ribs observed at Re 30000 are greater than those anticipated by DENG Honghu et al. [24] for $90^{\circ}$ ribs inside a square channel with a 40\% higher blockage ratio at Re 20000 . Also, the THPo of discrete $\mathrm{V}$ and $\mathrm{W}$-ribs are comparable with that of continuous $\mathrm{V}$ and $\mathrm{W}$-ribs with higher blockage ratios studied by Krishnaswamy and Sivan [25]. The above findings reiterate the fact that, discrete $\mathrm{V}$ and $\mathrm{W}$-ribs can produce superior thermohydraulic performances inside cooling passages with low aspect ratios and hence they can be deployed in regions exposed to extreme temperatures to deliver high thermal performance. Besides, the discrete ribs aid in improving the power-to-weight ratio as the ribs can produce high thermohydraulic performances for low blockage ratios.

Table.3 $\mathrm{Nu} / \mathrm{Nu}$ o comparison

\begin{tabular}{|c|c|c|c|c|c|c|c|}
\hline & Type of Ribs & $\underline{\mathrm{AR}}$ & $\underline{\mathbf{e} / \mathbf{D}_{\mathbf{h}}}$ & $\underline{\mathbf{P} / \mathbf{e}}$ & $\underline{\alpha}$ & $\underline{\mathbf{R e}}$ & $\underline{\mathrm{Nu} / \mathrm{Nu}_{0}}$ \\
\hline & Discrete V-ribs & $1: 5$ & 0.06 & 12 & $45^{\circ}$ & \multirow{2}{*}{$\begin{array}{l}30000 / \\
45000 / \\
60000 / \\
75000\end{array}$} & $3.4 / 2.7 / 2.3 / 2$ \\
\hline Present Study & Discrete W- ribs & $1: 5$ & 0.06 & 12 & $30^{\circ}$ & & $3.6 / 2.8 / 2.4 / 2.1$ \\
\hline $\begin{array}{c}\text { Han and Zhang } \\
\text { [3] }\end{array}$ & V-shaped broken ribs & $1: 1$ & 0.0625 & 10 & $45^{\circ}$ & $\begin{array}{l}30000 / \\
45000 / \\
60000 / \\
75000\end{array}$ & 3.1/2.7/2.6/2.5 \\
\hline Ekkad and Han [4] & V-shaped broken ribs & $1: 1$ & 0.125 & 10 & $60^{\circ}$ & $\begin{array}{l}30000 / \\
60000\end{array}$ & $2.9 / 2$ \\
\hline Wright et al. [7] & $\begin{array}{l}\text { Discrete V- ribs } \\
\text { Discrete W- ribs }\end{array}$ & $4: 1$ & 0.078 & 10 & $45^{\circ}$ & 30000 & $\begin{array}{c}3.15 \\
3.4\end{array}$ \\
\hline Fu et al. [9] & Angled ribs & $1: 4$ & 0.078 & 10 & $45^{\circ}$ & 30000 & 2.7 \\
\hline \multirow{2}{*}{ Prashant et al. [22] } & V-ribs & \multirow{2}{*}{$1: 1$} & \multirow[t]{2}{*}{0.125} & \multirow[t]{2}{*}{16} & \multirow[t]{2}{*}{$45^{\circ}$} & \multirow{2}{*}{$\begin{array}{l}30000 / \\
60000\end{array}$} & $3.0 / 2.6$ \\
\hline & W-ribs & & & & & & $2.5 / 2.1$ \\
\hline \multirow{2}{*}{$\begin{array}{c}\text { Krishnaswamy and Sivan } \\
\text { [25] }\end{array}$} & V-ribs & \multirow{2}{*}{$1: 4$} & 0.0729 & 10 & \multirow[t]{2}{*}{$45^{\circ}$} & \multirow{2}{*}{$\begin{array}{l}40000 / \\
60000 / \\
80000\end{array}$} & $3.4 / 2.7 / 2.4$ \\
\hline & W-ribs & & 0.0833 & 8.75 & & & $3.3 / 2.8 / 2.6$ \\
\hline
\end{tabular}

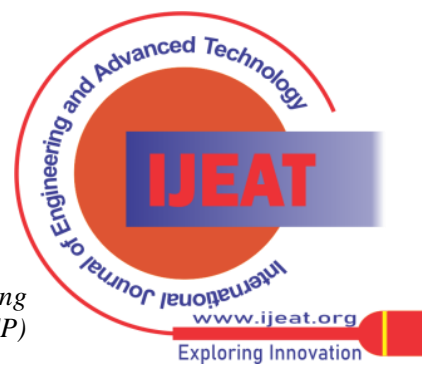




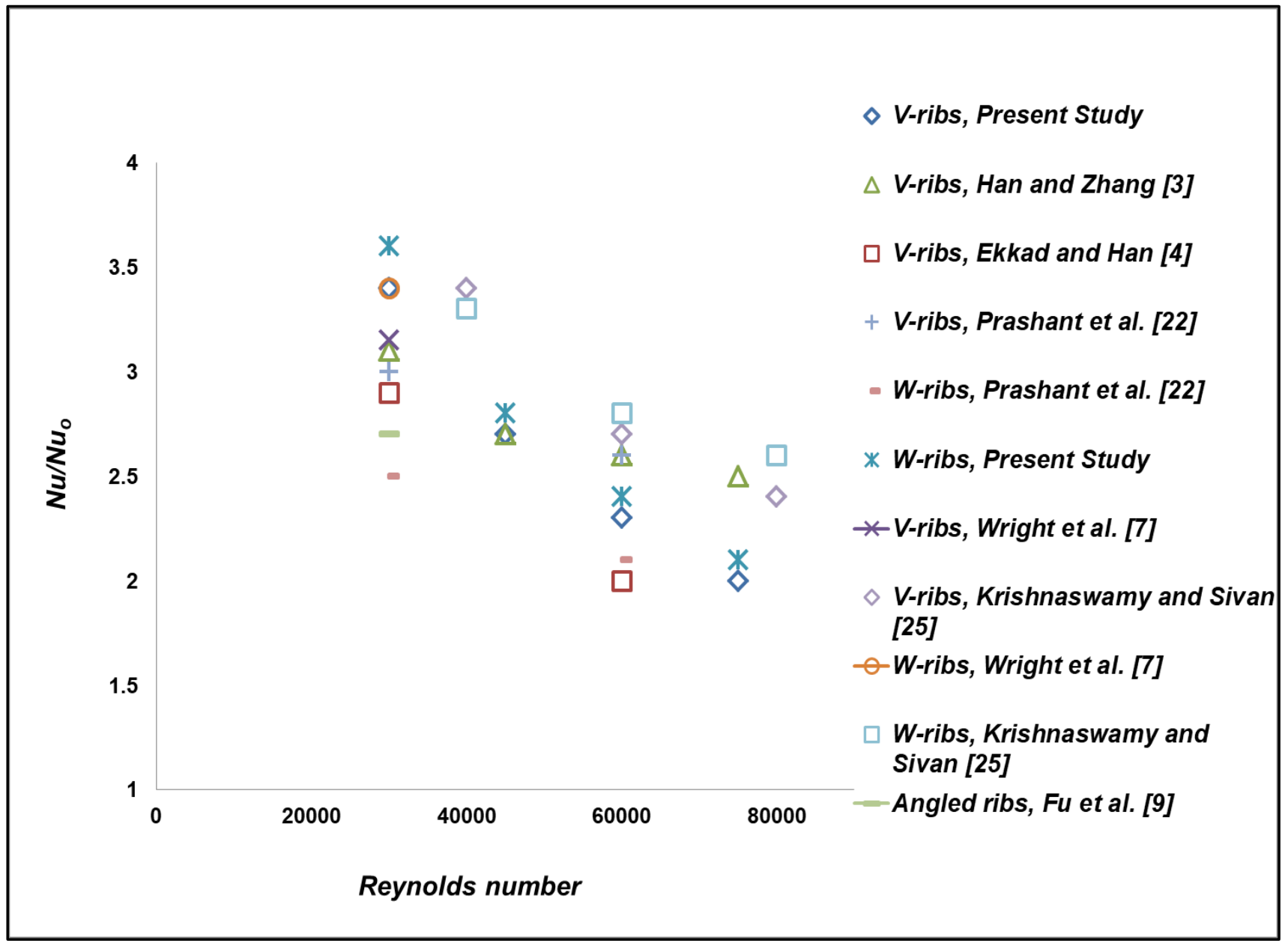

Fig. 16 Comparison of $\mathrm{Nu} / \mathrm{Nu}$ with published results

\begin{tabular}{|c|c|c|c|c|c|c|c|}
\hline & Type of Ribs & $\underline{\mathbf{A R}}$ & $\underline{\mathbf{e} / \mathbf{D}_{\mathbf{h}}}$ & $\underline{\mathbf{P} / \mathbf{e}}$ & $\underline{\alpha}$ & $\underline{\mathbf{R e}}$ & $\underline{\mathbf{T H P}}_{0}$ \\
\hline \multirow[b]{2}{*}{ Present Study } & $\begin{array}{l}\text { Discrete } \\
\text { V-ribs }\end{array}$ & \multirow{2}{*}{$1: 5$} & \multirow{2}{*}{0.06} & \multirow{2}{*}{9} & \multirow{2}{*}{$30^{\circ}$} & \multirow{2}{*}{$\begin{array}{l}30000 / \\
45000 / \\
60000 / \\
75000\end{array}$} & $3.2 / 2.4 / 2 / 1.7$ \\
\hline & $\begin{array}{l}\text { Discrete } \\
\text { W-ribs }\end{array}$ & & & & & & 3/2.3/1.95/1.65 \\
\hline \multirow[t]{2}{*}{ Wright et al. [7] } & $\begin{array}{l}\text { Discrete } \\
\text { V-ribs }\end{array}$ & \multirow{2}{*}{$4: 1$} & \multirow{2}{*}{0.078} & \multirow{2}{*}{10} & \multirow{2}{*}{$45^{\circ}$} & \multirow{2}{*}{30000} & 1.55 \\
\hline & $\begin{array}{l}\text { Discrete } \\
\text { W- ribs }\end{array}$ & & & & & & 1.55 \\
\hline Smith et al. [19] & Angled ribs & $1: 6$ & 0.058 & 10 & $45^{\circ}$ & $\begin{array}{c}25000 / \\
50000 / \\
75000\end{array}$ & $1.5 / 1.2 / 1$ \\
\hline \multirow{2}{*}{ Prashant et al. [22] } & V-ribs & \multirow[b]{2}{*}{1.1} & \multirow[b]{2}{*}{0.125} & \multirow[b]{2}{*}{16} & \multirow[b]{2}{*}{$45^{\circ}$} & \multirow{2}{*}{$\begin{array}{l}30000 / \\
60000\end{array}$} & $1.55 / 1.3$ \\
\hline & W-ribs & & & & & & $1.35 / 1.1$ \\
\hline $\begin{array}{l}\text { DENG Honghu et al. } \\
{[24]}\end{array}$ & Orthogonal ribs & $1: 1$ & 0.1 & - & $90^{\circ}$ & 20000 & 3 \\
\hline \multirow{2}{*}{$\begin{array}{l}\text { Krishnaswamy an Sivan } \\
\text { [25] }\end{array}$} & V-ribs & \multirow[t]{2}{*}{$1: 4$} & 0.0729 & 10 & \multirow[t]{2}{*}{$45^{\circ}$} & \multirow{2}{*}{$\begin{array}{c}40000 / 6000 \\
0 / 80000\end{array}$} & $2.4 / 1.8 / 1.6$ \\
\hline & W-ribs & & 0.0833 & 8.75 & & & $2.3 / 1.7 / 1.5$ \\
\hline
\end{tabular}

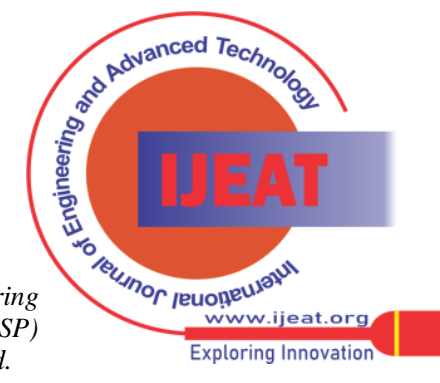




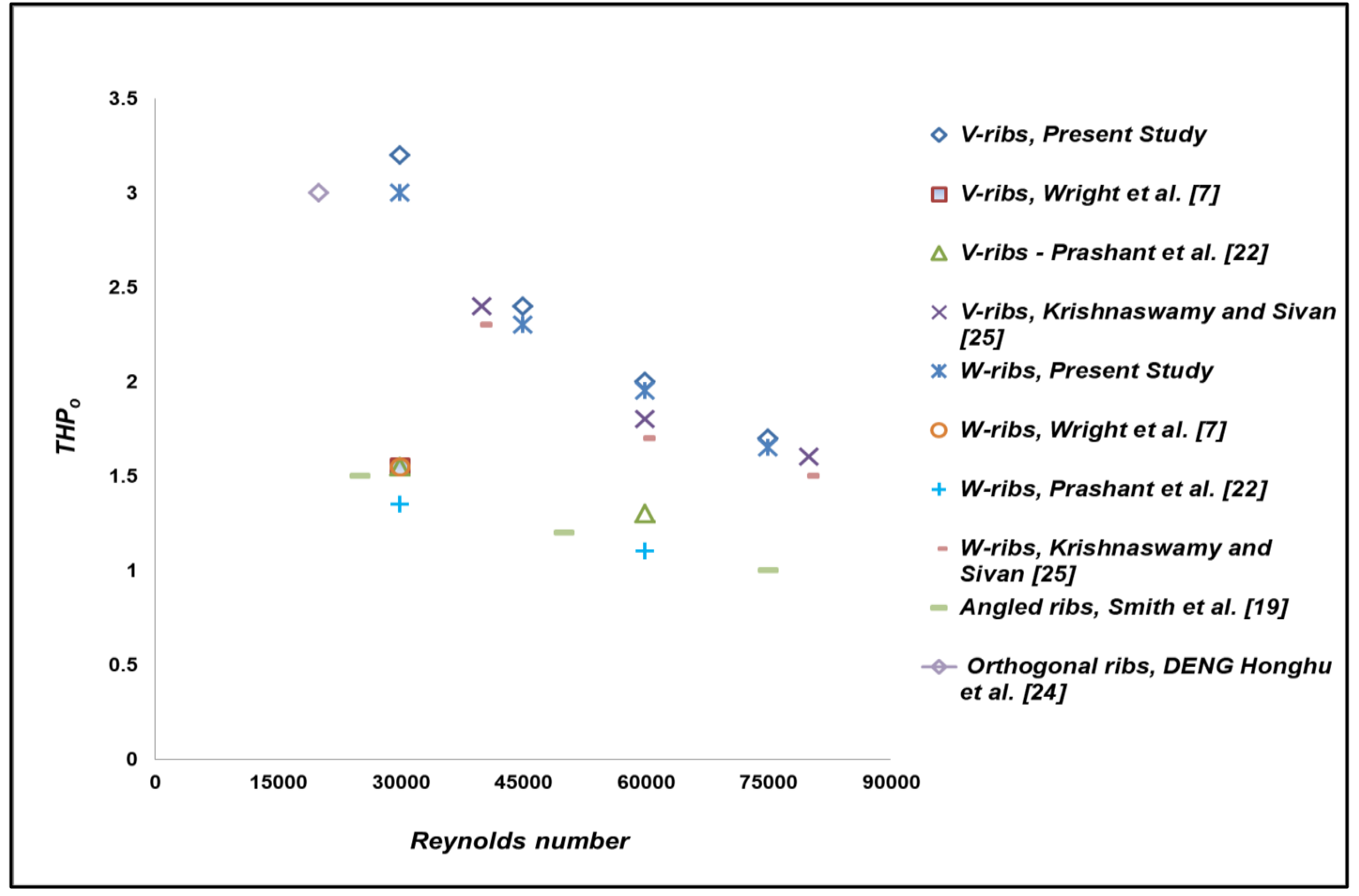

Fig.17 Comparison of THPo with published results

\section{V.CONCLUSIONS}

Nusselt number ratio $\left(\mathrm{Nu} / \mathrm{Nu}_{o}\right)$ and Thermohydraulic Performance $\left(T H P_{o}\right)$ values for the experimented $R e$ range 30000-75000 are found to reasonably good for both the rib profiles. The inferences drawn from the results are as shown below:-

\section{Discrete V-ribs}

- For Re range investigated, wall temperatures along the span length $0.5 \mathrm{w}$ (centreline) and nearby regions are found to be lesser than other regions due to the collective effect of stronger secondary flow induced by the apex and the acceleration induced by the gap.

- Improvement in secondary flow in the direction of stream is observed for all $R e$ which is speculated to be because of the increment in coolant momentum induced range, heat transfer in the side wall regions is observed to be lowest which subsequently improved with $R e$.

- The magnitude of heat transfer coefficients between successive ribs varied along the stream and the variations for the experimented range of $R e$ are comparable with the uncertainty estimated in measurement of Nusselt number.

- Between the span lengths, variation along $0.5 \mathrm{w}$ is found to be less than $0.25 \mathrm{w}$ due to abrupt increase in velocity at the gap between the rib arms. The influence of acceleration on heat transfer is noticed even along 0.25 w span length and the same is found to be increasing with $R e$. The maximum average variation is $11 \%$ along the span length $0.25 \mathrm{w}$ at $R e$ 30000. As the Re increased, variation reduced. by the discreteness. In general, for the experimented $R e$

- As the $R e$ increased, heat transfer coefficients also increased. Maximum increase of $11.5 \%$ is observed between $\operatorname{Re} 45000$ and 60000. At Re 75000, the overall increment reduced because of reduction in intensity of secondary flow along the stream as a result of coolant diversion. The $\mathrm{Nu} / \mathrm{Nu}_{\mathrm{o}}$ values are observed to be 3.4 and 2 corresponding to $R e 30000$ and 75000 respectively. $\mathrm{Nu} / \mathrm{Nu}_{\mathrm{s}}$ values estimated for $\mathrm{Re} 30000$ and 75000 are 2.7 and 1.8 respectively.

- Friction factor ratio $\left(f / f_{o}\right)$ increased as the $R e$ increased. The values ranged from 1.2-1.7 for the $R e$ range investigated. Between consecutive $R e$, maximum pressure drop increment of $17 \%$ is observed between $R e$ 30000 and 45000. Between the Re 60000 and 75000, increment is found to be lowest at $6 \%$. Appreciable reduction in $f / f_{o}$ increment between $\operatorname{Re} 60000$ and 75000 is because of the coolant diversion towards side walls which subsequently reduced the overall pressure drop. The $f / f_{s}$ values are higher than $f / f_{o}$ and they range from 1.3-2.1.

- The $T H P_{o}$ values corresponding to the maximum and minimum $R e$ experimented are 3.2 and 1.7. For $R e$ 45000 and 60000 , the thermohydraulic performances estimated are 2.4 and 2. $T H P_{s}$ values are comparatively lesser than $T H P_{o}$ and are estimated to be 2.6 and 1.5 for Re 30000 and 75000.

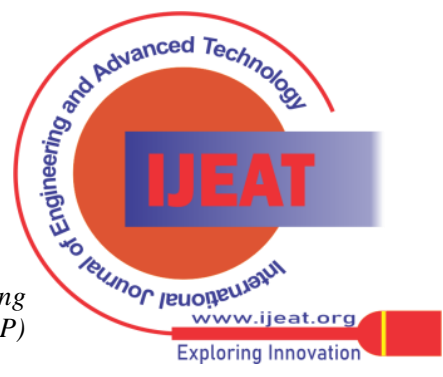


- From the inferences drawn, discrete V-rib profile is recommended for deployment in aspect ratio 1:5 channel for Re ranging from 45000 to 75000 .

\section{Discrete W-ribs}

- $\quad$ For the experimented Re range, heat transfer along the span is uniform due to the effect of superior secondary flow produced by the two apexes. The intensity of heat transfer varied in the direction of stream and the variation along $0.5 \mathrm{w}$ span length is found to be marginally lesser than $0.25 \mathrm{w}$ due to influence of discreteness.

- Unlike discrete V-ribs, variations in heat transfer in the direction of stream increased with $R e$ and is found to be highest at $R e$ 60000. Average variation for span lengths $0.25 \mathrm{w}$ and $0.5 \mathrm{w}$ are estimated to be $25 \%$ and $19 \%$. At $\operatorname{Re} 75000$, as a result of reduction in intensity of secondary flow due to coolant diversion, variation along $0.25 \mathrm{w}$ and $0.5 \mathrm{w}$ reduced and are estimated to be $19 \%$ and $17 \%$ respectively.

- The enhancements achieved along the span lengths $0.25 \mathrm{w}$ and $0.5 \mathrm{w}$ are comparable with a maximum difference of $2.5 \%$ at $\operatorname{Re} 75000$. The heat transfer coefficient increased with $R e$ and the increase between successive $R e$ is observed to be approximately $9.5 \%$ for Re up to 60000. Between Re 60000 and 75000, increase in enhancement is lowest as a result of coolant diversion and is calculated to be $2 \%$ for the span length $0.25 \mathrm{w}$ and $6 \%$ for the span length $0.5 \mathrm{w}$. The area averaged Nusselt number ratios $\left(\mathrm{Nu} / \mathrm{Nu}_{o}\right)$ for $\mathrm{Re} 30000$ and 75000 are 3.6 and 2.1 respectively. $N u / N u_{s}$ for the same $R e$ are 2.9 and 1.9.

- The $f / f_{o}$ values corresponding to the experimented $R e$ range from 1.6-2. For $R e$ up to 60000, increment in $f / f_{0}$ between consecutive $R e$ is noticed to be the same at $6 \%$. Between the Re 60000 and 75000, increment in $f / f_{0}$ is observed to be highest at $11 \%$ due to sudden influx of coolant between the converging rib arms. In comparison to $f / f_{o}$ values, friction factor ratio $\left(f / f_{s}\right)$ values are higher and they range from 1.7-2.4.

- The maximum and minimum thermohydraulic performances for Re 30000 and 75000 are 3 and 1.65 . $T H P_{s}$ values are comparatively lesser than $T H P_{o}$ and the values are 2.4 and 1.5 for $R e 30000$ and 75000 respectively.

- From the inferences drawn, discrete W-rib profile is recommended for deployment in aspect ratio 1:5 channel for Re ranging from 30000 to 75000 .

\section{Nomenclature}

$\begin{array}{ll}\alpha & \text { Angle of attack } \\ \mathrm{P} & \text { Rib pitch, mm } \\ \mathrm{e} & \text { Height of the rib, mm } \\ \mathrm{D}_{\mathrm{h}} & \text { Hydraulic diameter of test section, mm } \\ \mathrm{W} & \text { Width of the test section, mm } \\ \mathrm{H} & \text { Height of the test section, } \mathrm{mm} \\ \mathrm{v} & \text { Velocity of air, } \mathrm{m} / \mathrm{s} \\ \mathrm{w} & \text { Width of the ribbed wall, mm } \\ \dot{\mathrm{m}} & \text { mass flow rate, Kg/s } \\ \mathrm{h} & \text { Local heat transfer coefficient, W/m } \mathrm{m}^{2}-\mathrm{K} \\ \mathrm{h}_{\mathrm{avg}} & \text { Span averaged heat transfer coefficient, } \\ \mathrm{W} / \mathrm{m}^{2}-\mathrm{K} & \end{array}$

$\overline{\mathrm{h}}$ ribbed wall, $\mathrm{W} / \mathrm{m}^{2}-\mathrm{K}$

Area averaged heat transfer coefficient for

$\overline{\mathrm{h}}_{\mathrm{s}} \quad$ Area averaged heat transfer coefficient for smooth wall, $\mathrm{W} / \mathrm{m}^{2}-\mathrm{K}$

Re Reynolds number

$\mathrm{Nu} \quad$ Area averaged Nusselt number for ribbed

wall

$\mathrm{Nu}_{\mathrm{s}} \quad$ Area averaged Nusselt number for smooth

wall

$\mathrm{Nu}_{0} \quad$ Nusselt number for fully developed turbulent flow in a smooth circular tube (Dittus- Boelter correlation)

$\begin{array}{ll}\operatorname{Pr} & \text { Prandtl number } \\ \rho & \text { Density of air, Kg/m } \\ \mathrm{k} & \text { Thermal Conductivity of air, W/m-K } \\ \mathrm{Q}_{\text {input }} & \text { Heat input, } \mathrm{W} \\ \mathrm{Q}_{\text {loss }} & \text { Heat loss, } \mathrm{W} \\ \mathrm{Q}_{\text {net }} & \text { Net heat input, W } \\ \mathrm{A} & \text { Effective ribbed surface area, } \mathrm{m}^{2} \\ \mathrm{~L} & \text { Length between the pressure taps, } \mathrm{m} \\ \mathrm{T}_{\text {bulk }} & \text { Local bulk temperature of air, } \mathrm{K} \\ \mathrm{T}_{\text {bin }} & \text { Bulk air inlet temperature, } \mathrm{K} \\ \mathrm{T}_{\text {bout }} & \text { Bulk air outlet temperature, } \mathrm{K} \\ \mathrm{T}_{\text {wall }} & \text { Local wall temperature of air, } \mathrm{K} \\ \mathrm{C}_{\mathrm{p}} & \text { Specific heat of air, J/Kg K } \\ \mathrm{I} & \text { Current } \\ \mathrm{V} & \text { Voltage } \\ \mathrm{f} & \text { Friction factor for ribbed wall } \\ \mathrm{f}_{\mathrm{s}} & \text { Friction factor for smooth wall } \\ \mathrm{f}_{\mathrm{o}} & \text { Friction factor for fully developed } \\ & \end{array}$
turbulent flow in a smooth tube (Blasius equation )

$\eta_{0} \quad$ Thermal Hydraulic Performance with respect to Dittus-Boelter correlation $\left(\mathrm{THP}_{\mathrm{o}}\right)$

$\eta_{\mathrm{s}} \quad$ Thermal Hydraulic Performance with respect to smooth wall $\left(\mathrm{THP}_{\mathrm{s}}\right)$

$\Delta \mathrm{P} \quad$ Pressure drop across the ribbed section,

$\mathrm{N} / \mathrm{m}^{2}$

$\Delta \mathrm{P}_{\mathrm{s}} \quad$ Pressure drop across the smooth section,

$\mathrm{N} / \mathrm{m}^{2}$

A Ampere

V Volt

$\mathrm{mV} \quad$ Millivolt

W Watt

Pa Pascal

\section{REFERENCES}

1. Han JC, Zhang YM, Lee CP (1991) Augmented Heat Transfer in Square Channels With Parallel, Crossed, and V-Shaped Angled Ribs. Journal of Heat Transfer 113 (3):590-596. https://doi.org/10.1115/1.2910606

2. Lau SC, Kukreja RT, Mcmillin RD (1991) Effects of V-Shaped Rib Arrays on Turbulent Heat Transfer and Friction of Fully Developed Flow in a Square Channel. International Journal of Heat and Mass Transfer 34 (7): 1605-1616. https://doi.org/10.1016/00179310(91)90140-A

3. Han JC, Zhang YM (1992) High Performance Heat Transfer Ducts with Parallel Broken and V-Shaped Broken Ribs. International Journal of Heat and Mass Transfer 35 (2): 513-523. https://doi.org/10.1016/0017-9310(92)90286-2

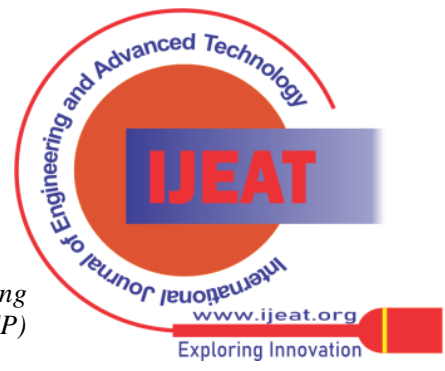




\section{Effect of Discrete Ribs on Heat Transfer and Friction Inside Narrow Rectangular Cross Section Cooling Passage (AR=1:5) of Gas Turbine Blade}

4. $\quad$ Ekkad SV, Han JC (1997) Detailed Heat Transfer Distributions in Two-Pass Square Channels with Rib Turbulators. International Journal of Heat and Mass Transfer 40(11): 2525-2537. PI1: S00179310(96)00318-3

5. Tzeng SC, Mao CP (2001) Heat Transfer in a Radially Rotating Four-Pass Serpentine Channel with Staggered Half-V Rib Turbulators. Journal of Heat Transfer 123: 39-50. https://doi.org/10.1115/1.1338130

6. Al-Hadhrami L, Griffith T, Han JC (2003) Heat Transfer in TwoPass Rotating Rectangular Channels $(A R=2)$ with Five Different Orientations of 45 Deg V-Shaped Rib Turbulators. Journal of Heat Transfer 125 (2): 232-242. https://doi.org/10.1115/1.1561455

7. Wright LM, Fu WL, Han JC (2004) Thermal Performance of Angled, V-Shaped, and W-Shaped Rib Turbulators in Rotating Rectangular Cooling Channels (AR 4: 1). Journal of Turbomachinery 126: 604-614. https://doi.org/10.1115/1.1791286

8. Gao X, Sunden B (2004) PIV Measurement of the Flow Field in Rectangular Ducts with $60^{\circ}$ Parallel, Crossed and V-Shaped Ribs. Experimental Thermal and Fluid Sciences 28: 639-653. https://doi.org/10.1016/j.expthermflusci.2003.10.005

9. Fu WL, Wright LM, Han JC (2005) Heat Transfer in Two-Pass Rotating Rectangular Channels AR 1:2 and AR 1: 4 With 45 Deg Angled Rib Turbulators. 127: 164-174 https://doi.org/10.1115/1.1791649

10. Khan RK, Ali MAT, Akhanda MAR (2006) Heat Transfer Augmentation in Developing Flow through a Ribbed Square Duct. Journal of Thermal Science 15 (3): 251-256. https://doi.org/10.1007/s11630-006-0251-z

11. Maurer M, Wolfersdorf JV (2007) An Experimental and Numerical Study of Heat Transfer and Pressure Loss in a Rectangular Channel with V-Shaped Ribs. Journal of Turbomachinery 129: 800-806, https://doi.org/10.1115/1.2720507

12. Gupta A, Sriharsha V, Prabhu SV, Vedula RP (2008) Local Heat Transfer Distribution in a Square Channel with $90^{\circ}$ Continuous, $90^{\circ}$ Saw Tooth Profiled and $60^{\circ}$ Broken Ribs. Experimental Thermal and Fluid Sciences 32. 997-1010. https://doi.org/10.1016/j.expthermflusci.2007.11.015

13. Sriharsha V, Prabhu SV, Vedula RP (2009) Influence of Rib Height on the Local Heat Transfer Distribution and Pressure Drop in a Square Channel with $90^{\circ}$ Continuous and $60^{\circ}$ V-Broken Ribs. Applied Thermal Engineering 29 (11-12): 2444-2459. https://doi.org/10.1016/j.applthermaleng.2008.12.015

14. Alkhamis NY, Rallabandi AP, Han JC (2011) Heat Transfer and Pressure Drop Correlations for Square Channels With V-Shaped Ribs at High Reynolds numbers. Journal of Heat Transfer 133: 1-8. https://doi.org/10.1115/1.4004207

15. Baraskar S, Aharwal KR, Lanjewar A (2012) Experimental Investigation of Heat Transfer and Friction Factor of V-Shaped Rib Roughed Duct with and without Gap. International Journal of Engineering Research and Applications 2 (6): 1024-1031. ISSN: 2248-9622

16. Lamont J, Kaminski C (2013) Heat Transfer Enhancement in Narrow Diverging Channels. Journal of Turbomachinery 135: 1-7. https://doi.org/10.1115/1.4007740

17. Kumar S, Amano RS (2014) Experimental Investigation of Hea Transfer and Flow Using V and Broken V Ribs within Gas Turbine Blade Cooling Passage. Heat and Mass Transfer/Waerme- Und Stoffuebertragung 51 (5): 631-647. https://doi.org/10.1007/s00231$\underline{014-1436-8}$

18. Xie G, Liu J, Ligrani P, Sunden B (2014) Flow Structure and Hea Transfer in a Square Passage with Offset Mid-Truncated Ribs. International Journal of Heat and Mass Transfer 71: 44-56. https://doi.org/10.1016/j.ijheatmasstransfer.2013.12.005

19. Smith M A, Mathison RM, Dunn MG (2014) Heat Transfer for High Aspect Ratio Rectangular Channels in a Stationary Serpentine Passage With Turbulated and Smooth Surfaces. Journal of Turbomachinery 136: 1-11. https://doi.org/10.1115/1.4025307

20. Ghoake NG, Rao C, Arakerimath RR (2016) Flow and Heat Transfer Analysis of Various Ribs for Forced Convection Heat Transfer. Journal of Emerging Technologies and Innovative Research 3 (7) 42-47. JETIR1607010

21. Abraham S, Vedula RP (2016) Heat Transfer and Pressure Drop Measurements in a Square Cross-Section Converging Channel with $\mathrm{V}$ and W Rib Turbulators. Experimental Thermal and Fluid Sciences 70: 208-219. https://doi.org/10.1016/j.expthermflusci.2015.09.003

22. Prashant S, Ravi BV, Ekkad SV (2016) Experimental and Numerica Study of Heat Transfer Due to Developing Flow in a Two-Pass Rib Roughened Square Duct. International Journal of Heat and Mass Transfer 102 : $1245-1256$ https://doi.org/10.1016/j.ijheatmasstransfer.2016.07.015
23. Ravi BV, Prashant S, Ekkad SV (2017) Numerical Investigation of Turbulent Flow and Heat Transfer in Two-Pass Ribbed Channels. International Journal of Thermal Sciences 112: 31-43. https://doi.org/10.1016/j.ijthermalsci.2016.09.034

24. Deng H, Li H, Tao Z, Qiu L, Zhu J (2020) Effect of Blockage Ratio on Heat Transfer and Pressure Drop in Rotating Ribbed Channels at High Rotation Numbers. Journal of Thermal Science 29. https://doi.org/10.1007/s11630-020-1275-5

25. Krishnaswamy K, Sivan S (2021) Improvement in thermal hydraulic performance by using continuous $\mathrm{V}$ and $\mathrm{W}$-Shaped rib turbulators in gas turbine blade cooling application. Case Studies in Thermal Engineering, https://doi.org/10.1016/j.csite.2021.100857.

26. Kline S, McClintock F (1953) Describing uncertainties in Singlesample experiments. Mech. Eng 75(1): 3-8.

\section{AUTHORS PROFILE}

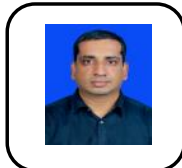

Karthik Krishnaswamy, is currently working in Ministry of Defence. He holds a Bachelor of Engineering degree from Regional Engineering College, Rourkela (Presently NIT, Rourkela) and M.Tech degree in Mechanical Engineering from IIT, Bombay. He is currently presently pursuing Ph.D (Part-time) from National Institute of Technology, Tiruchirappalli, Tamil Nadu. His research interests include Heat Transfer enhancement in Gas Turbines and Fluid Mechanics.

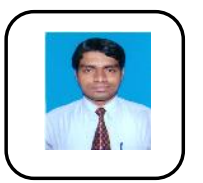

Srikanth Salyan is currently working as Assistant Professor in the Department of Aeronautical Engineering, Dayananda Sagar College of Engineering, Bangalore, Karnataka, India. He has a Doctoral degree in Mechanical Engineering from National Institute of Technology, Tiruchirappalli, Tamilnadu, India. His research interests are Renewable Energy, Electronic Cooling, Heat Transfer enhancement and Thermal Energy Storage respectively.

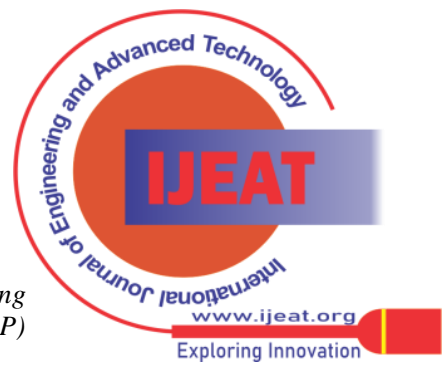

